\title{
Inflammation: the link between comorbidities, genetics, and Alzheimer's disease
}

\author{
Estella A. Newcombe ${ }^{1 *}$, Judith Camats-Perna ${ }^{1}$, Mallone L. Silva ${ }^{1}$, Nicholas Valmas'², Tee Jong Huat ${ }^{1,3}$ \\ and Rodrigo Medeiros ${ }^{1 *}$ (D)
}

\begin{abstract}
Alzheimer's disease (AD) is a neurodegenerative disorder, most cases of which lack a clear causative event. This has made the disease difficult to characterize and, thus, diagnose. Although some cases are genetically linked, there are many diseases and lifestyle factors that can lead to an increased risk of developing $A D$, including traumatic brain injury, diabetes, hypertension, obesity, and other metabolic syndromes, in addition to aging. Identifying common factors and trends between these conditions could enhance our understanding of AD and lead to the development of more effective treatments. Although the immune system is one of the body's key defense mechanisms, chronic inflammation has been increasingly linked with several age-related diseases. Moreover, it is now well accepted that chronic inflammation has an important role in the onset and progression of AD. In this review, the different inflammatory signals associated with $A D$ and its risk factors will be outlined to demonstrate how chronic inflammation may be influencing individual susceptibility to AD. Our goal is to bring attention to potential shared signals presented by the immune system during different conditions that could lead to the development of successful treatments.
\end{abstract}

Keywords: Alzheimer's disease, Microglia, Aging, Neuroinflammation, APOE4, TREM2, CD33, Diabetes, TBI, Obesity

\section{Background}

Alzheimer's disease (AD), classified as a type of dementia, is a neurodegenerative disease which has come into the spotlight due to its high prevalence in the elderly. Currently, the disease impacts 1 in 10 people over 65 years of age and 1 in 3 people over 85 . Initial symptoms include memory loss, cognitive impairment, and confusion, progressing to full debilitation over time. The neuropathological processes associated with the disease, including the accumulation of amyloid plaques and neurofibrillary tangles (NFTs), inflammation, and synaptic and neuronal loss, are predicted to build up for 10 20 years before the clinical symptoms arise, representing the largest obstacle in the development of effective treatments for the disease (Fig. 1).

\footnotetext{
*Correspondence: e.newcombe@uq.edu.au; rodrigo.medeiros@neurula.org; r.medeiros@uq.edu.au

${ }^{1}$ Neurula Laboratory, Clem Jones Centre for Ageing Dementia Research, Queensland Brain Institute, The University of Queensland, Building 79, Brisbane 4072, QLD, Australia

Full list of author information is available at the end of the article
}

Currently, two classes of drugs-cholinesterase inhibitors (i.e., donepezil, galantamine and rivastigmine) and $\mathrm{N}$-methyl-D-aspartate receptor (NMDAR) antagonists (i.e., memantine) - are approved to treat $\mathrm{AD}$; however, the efficacy of these drugs leaves a lot to be desired. No new drug has been approved since Namenda (memantine) in 2003, despite the extensive number of clinical trials aimed at tackling the disease [1]. Although the goal is to cure $\mathrm{AD}$ and reverse its harmful effects, any efficacious strategy to slow or prevent the progression of the disease would have a tremendous global socio-economic impact in the current epidemiological scenario. To design such a strategy, however, we require a better understanding of how $\mathrm{AD}$ starts and what makes some individuals resilient to the disease. The hope is that this knowledge will lead to the identification of cellular and molecular events that could be targeted therapeutically.

In this review, we highlight how risk and protective factors that are associated with $\mathrm{AD}$ affect the immune system. We also discuss the evidence indicating that the long-lasting dysregulation of inflammatory responses 


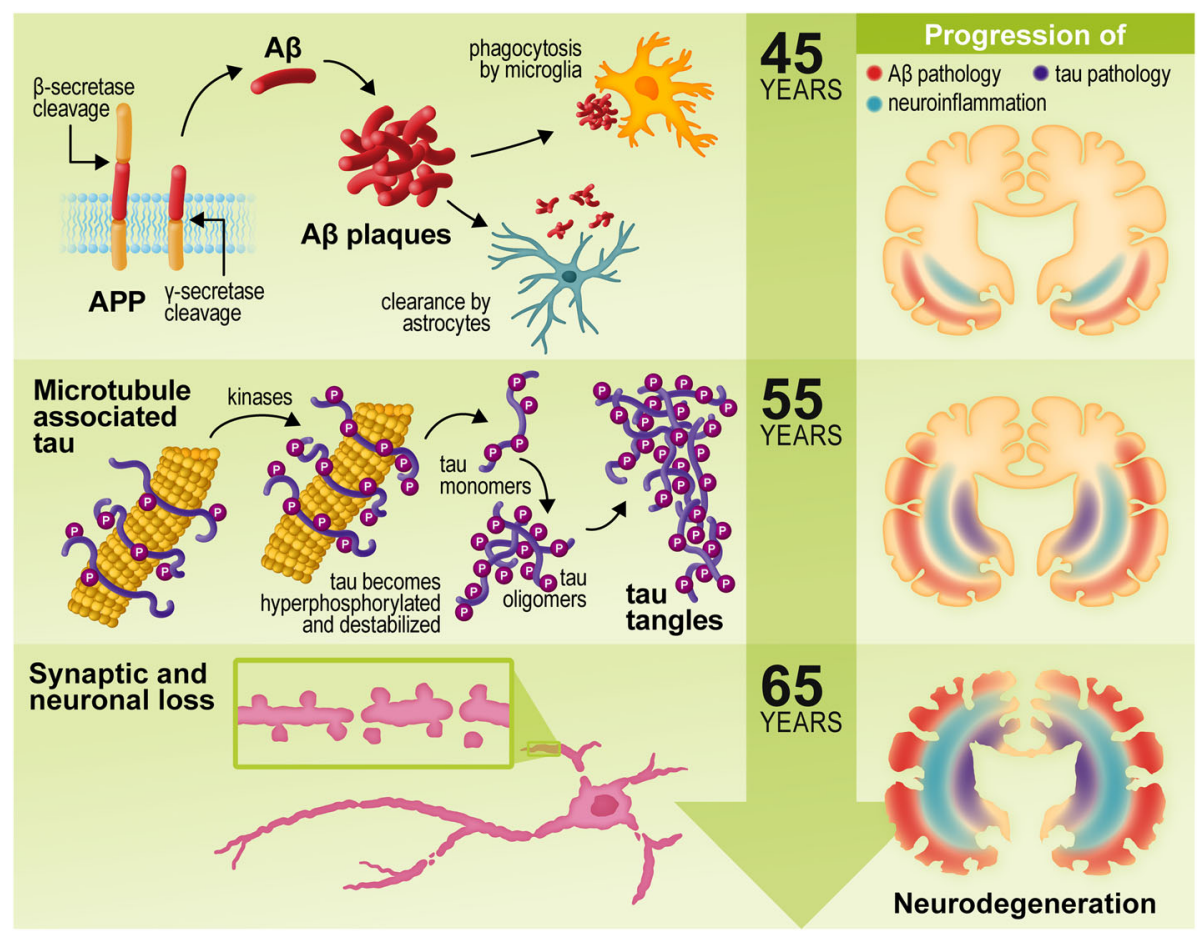

Fig. 1 The pathogenic hallmarks of $A D$ in the human brain over time. In the earliest stages of $A D$, the formation of $A \beta$ occurs due to abnormal cleavage of amyloid precursor protein (APP) by $\beta$ - and $\gamma$-secretases, whereas it is normally cleaved by $a$ - and $\gamma$-secretases. A $\beta$ monomers are intrinsically disordered and have a propensity to oligomerize and aggregate into $A \beta$ plaques. $A \beta$ activates microglia and astrocytes, causing them to clear $A \beta$ via phagocytosis and proteolysis. The presence of $A \beta$ has also been linked to the hyperphosphorylation and destabilization of tau and the subsequent formation of tau tangles. Inflammatory activation and signaling can also cause further production of $A \beta$. Tau pathology is observed approximately 10 years after the initiation of $A \beta$ aggregation. Tau is a microtubule-associated protein that is predominately found in neurons, where it is regulated by phosphorylation and other post-translational modifications (i.e., acetylation, ubiquitylation) to stabilize microtubules, regulate axonal stability, and maintain cell function. While tau contains 2-3 mol of phosphate in the healthy brain, it can accumulate up to three times more phosphate in AD. This hyperphosphorylation lowers the affinity of tau for the microtubules, increases its resistance to degradation by proteases and the proteasome, and leads to its fibrillization and aggregation into neurofibrillary tangles, which ultimately causes neuronal loss and cognitive decline. The increase in $A \beta$ aggregation, inflammation, and tau hyperphosphorylation leads to a variety of downstream effects on neuronal synapses, including inhibition of LTP, impaired dendritic trafficking, increased excitotoxicity, and a reduction in synaptic density. This leads to synaptic loss and eventual neuronal loss approximately 20 years following initial disease pathogenesis, which is followed by the symptomatic cognitive decline

impact brain function, thereby facilitating the onset and progression of neurodegeneration in $\mathrm{AD}$. Although we provide some discussion of how the immune system responds to $\mathrm{AD}$, our major focus is to discuss how it triggers important features of the disease, namely $\beta$ amyloid $(\mathrm{A} \beta)$ accumulation, tau pathology, synaptic and neuronal loss, and cognitive impairment. We also highlight potential shared signals presented by the immune system during different conditions in the body and brain that could lead to the development of strategies for the management of the disease.

\section{The foundations of neuroinflammation}

Inflammation is a vital physiological immune response against a myriad of factors including infection, trauma, and disease. Not surprisingly, its failure provokes substantial detrimental effects. Contrasting examples of immune dysregulation are the deficiency of the immune response caused by the human immunodeficiency virus and the chronic immune activation in the autoimmune disease multiple sclerosis. In a proper response, immune cells are recruited to the area where the insult occurred via pro-inflammatory signaling pathways. Once recruited, these cells can initiate many different activities, such as increasing vascularization, recruiting additional immune cells via pro-inflammatory signaling, and initiating the phagocytosis of debris and pathogens. The mediators involved in the onset of systemic immune responses are pro-inflammatory and include transcriptional factors (e.g., NF-kB), peptides (e.g., bradykinin), cytokines (e.g., IL-1 $\beta$, IL-6, IL-18, TNF- $\alpha$, IFN- $\gamma$ ), chemokines (e.g., CCL2, CCL3, CXCL8), complement (e.g., C1q, C5), enzymes (e.g., COX-2, iNOS, LOX), lipids (e.g., $\mathrm{PGE}_{2}$ ), and coagulation factors (e.g., platelet activating factor). When the trigger of the response is successfully neutralized, immune cells shift 
their activity towards a pro-resolution phenotype via anti-inflammatory signaling, including lipoxins (e.g., $\mathrm{LXA}_{4}, \mathrm{RvE1}$ ) and cytokines (e.g., IL-10, IL-37, TGF- $\beta$ ). The resolution of inflammation involves the downregulation of pro-inflammatory mediators and the increased expression of anti-inflammatory mediators, with its major purposes being to promote the clearance of debris and the repair of the injured tissue [2]. Acute inflammatory events are resolved relatively quickly, with levels of inflammation returning to baseline; however, resolution is not achieved in cases of chronic inflammation (Fig. 2).

A similar sequence of events occurs in the brain, which has its own resident immune cells, microglia. In the healthy brain, microglia participate in several housekeeping functions, including the maintenance of synapses (i.e., elimination, pruning or maturation), neurogenesis, the regulation of cognitive functions, and immunological surveillance. In the immune context, these cells sense pathological stimuli and inflammatory signals, produce inflammatory signals, and are involved in phagocytosis. Notably, recent studies have shown that microglia are highly heterogeneous across the different regions of the brain [3, 4]. In general, the number of microglial cells remains steady from late

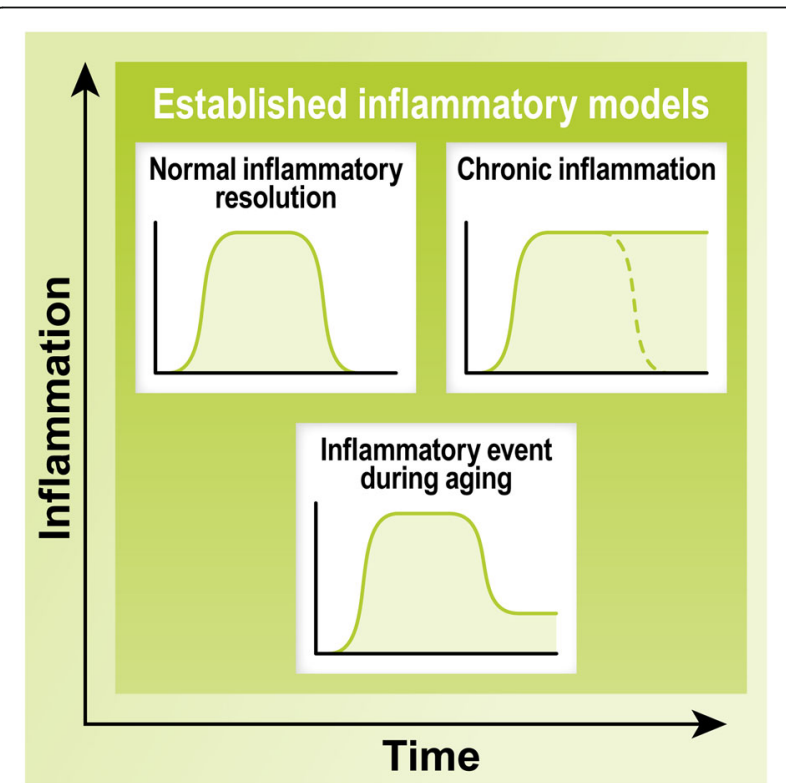

Fig. 2 Time-course of pro- and anti-inflammatory responses. The accepted model of acute inflammation shows the activation and resolution of inflammation that occurs due to pro- and then antiinflammatory modulators. These processes become dysfunctional during chronic inflammation where the resolution phase is not achieved due to excessive pro-inflammatory signaling. Considering more recent developments in the studies of inflammation, we propose a hypothetical model of inflammation during aging, in which an event is not resolved to a baseline inflammatory level, but leaves some residual pro-inflammatory effects (i.e., microglial priming) postnatal stages until old age due to the spatial and temporal coupling of proliferation and apoptosis [5], which occurs randomly throughout the brain [3]. At this stage, microglia are morphologically characterized by a small soma and ramified processes (Fig. 3). Upon activation, however, the self-renewal pattern shifts to selected clonal microglial expansion [3], in which activated cells acquire an amoeboid phenotype by shortening their cellular processes and enlarging their soma. At the molecular level, activated microglia upregulate the expression of many molecules (e.g., CD11b, Iba1, TLRs, CX3CR1, TREM2) and acquire antigen presentation features by expressing major histocompatibility complex-II (MHC-II), B7.1 and B7.2 (CD80/86). Proper priming of microglia during immune responses is tightly regulated by changes in the equilibrium of pro- and anti-inflammatory signals and is a fundamental step in the removal of pathogens and microbes by phagocytosis, as well as the clearance of toxic molecules, cell debris, remains of the extracellular matrix, myelin derivatives, and protein deposits (e.g., $A \beta, \alpha$-synuclein). In the resolution phase, the excess microglia are removed by a dual mechanism of cell egress and apoptosis to re-establish the stable microglial network [3].

Similar to microglia, astrocytes play multiple roles in organizing and maintaining brain structure and function. Mounting evidence suggests that astrocytes dynamically modulate information processing, signal transmission, neural and synaptic plasticity, and blood-brain barrier (BBB) homeostasis. Their role in immune responses, however, remains poorly understood. Gene transcriptome analyses in the mouse brain have revealed that astrocytes are highly immune reactive and upregulate unique sets of genes that can either promote or hinder recovery depending on the immunological trigger. For instance, astrocytes seem to display a protective molecular phenotype during ischemic events, whereas their molecular phenotype seems to be harmful following Escherichia coli (E. coli) lipopolysaccharide (LPS)-nduced inflammation [6]. In the retina, astrocytes produce lipoxins that exert anti-inflammatory and neuroprotective effects against acute and chronic injury [7]. Recent evidence has indicated that production of the cytokine interleukin (IL)-33 by astrocytes is an important step in microglial synapse engulfment and neural circuit development [8]. Moreover, it has been shown that the proinflammatory cytokine tumor necrosis factor- $\alpha$ (TNF- $\alpha$ ) signals through astrocytes to alter synaptic transmission and impair cognition in a mouse model of multiple sclerosis [9]. Although much of the detail of astrocyte heterogeneity remains elusive, it has been proposed that activation of the transcriptional factors, signal transducer and activator of transcription 3 (STAT3) and nuclear 


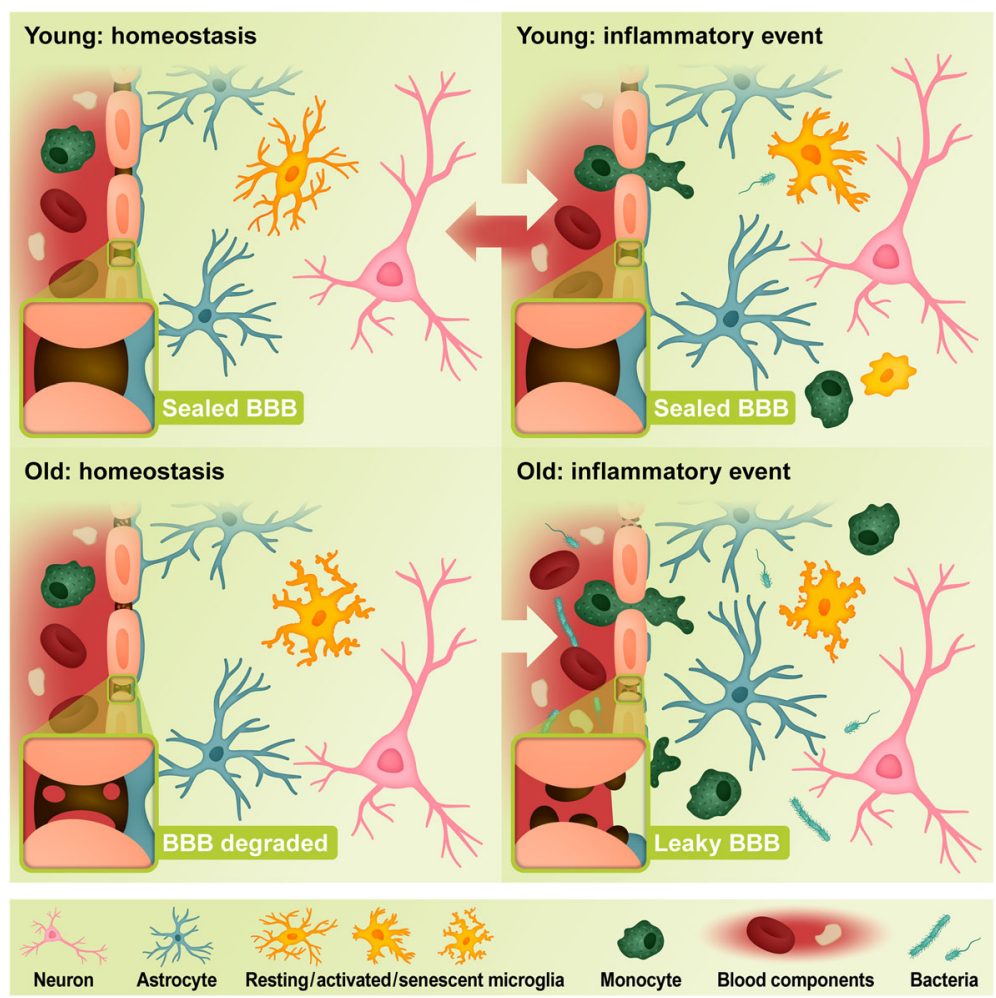

Fig. 3 Inflammatory responses in the young and old brain. The BBB is intact in the young brain, reinforced by tight junctions, endothelial cells, pericytes, and astrocytes (blue). During homeostasis, microglia (orange) perform a surveillance role with extended processes. Microglia and astrocytes are activated by an inflammatory event, during which the microglia prepare for phagocytosis to eliminate the inflammatory stimulus, such as during a bacterial infection following an injury. Peripheral immune cells such as monocytes (green) are also able to cross the BBB to enhance phagocytosis and debris clearance in the brain. After the inflammatory event, microglia in the young brain are able to return to their surveillance state. After a lifetime of such events, however, microglia in the aged brain acquire a primed state, where they exhibit persistent low-level inflammation during homeostasis. During aging, the BBB also becomes leaky. Primed microglia are fast to react to inflammatory stimuli, but have a high risk of becoming senescent and unable to perform phagocytosis and clear infection. If the microglia are no longer able to remove the infection, they continue to release inflammatory mediators, leading to increased inflammatory cell migration past the BBB, which is further permeabilized during disease

factor- $\mathrm{kB}(\mathrm{NF}-\kappa \mathrm{B})$, is at least in part related to their protective [10] and detrimental [11] phenotypes, respectively. Clearly, additional studies of the role of astrocytes in inflammation and immune regulation will have a tremendous impact in advancing our understanding of brain function during healthy and disease states.

\section{The effect of aging on microglia}

Aging is the most prevalent risk factor for AD. As individuals age, a gradual deterioration, known as immunosenescence, occurs in the peripheral and central components of immune system, raising susceptibility to infections and diseases. In the aged human brain, altered expression of several immune-related genes has been observed in distinct regions, a pattern that is exacerbated in $\mathrm{AD}$ [12]. Age-related changes in the brain have also been observed at the cellular level, with microglia showing substantial phenotypic changes. Grabert and colleagues have recently shown through genome-wide transcriptional profiling that aging impacts microglia in a non-uniform and regiondependent manner in mice. More importantly, they discovered that changes in immune-related genes, and to lesser extent bioenergetics-related genes, are largely associated with the region- and age-related diversity of these cells [4]. Microglia isolated post-mortem from aged human parietal cortex also show a distinct transcriptomic profile versus cells obtained from young subjects, in which genes associated with cell adhesion, axonal guidance, cell surface receptor expression, and actin assembly are particularly affected [13]. Morphologically, aged microglia from human cerebral cortex exhibit several abnormalities, including deramification, spheroid formation, gnarling, and fragmentation of processes (Fig. 3) [14].

Microglia are also highly affected by aging and disease at the molecular level. Using a newly developed high-dimensional single-cell proteomic mapping, Mrdjen and colleagues identified distinct populations of inflammatory cells, including microglia, in the adult mouse brain. 
Notably, they were also able to detect robust changes in the proteomic signature of these cells during aging, neurodegeneration and neuroinflammation [15]. Compared to cells from young mice, a subset of aged microglia expressed high levels of the phagocytosis-associated markers CD11c and CD14. Moreover, distinct populations of microglia were identified in the aged mouse brain, in which the reactive population expressed higher levels of CD11c, CD14, CD86, CD44, programmed death-ligand 1 and MHC-II, and lower levels of the microglial homeostatic checkpoint markers CX3CR1, MerTK (C-MER proto-oncogene tyrosine kinase), and Siglec- $\mathrm{H}$, compared to the non-reactive microglia [15]. Biochemically, aged microglia produce more reactive oxidative species and inflammatory cytokines [16], and they have also been found to suppress neural precursor activity in the mouse hippocampus [17]. TNF- $\alpha$, IL-1 $\beta$, and IL-6 are among the pro-inflammatory cytokines that are overproduced during aging, an effect which is thought to be caused by overstimulation of the transcription factor NF- $\mathrm{kB}$ when microglia undergo cellular senescence [12].

The overproduction of pro-inflammatory mediators leads to the sensitization of microglia, or age-related microglial priming (Figs. 2 and 3), whereby aged microglia produce an exaggerated, but inefficient, response to inflammatory stimuli. Wendeln and colleagues recently demonstrated that peripheral stimulation of mouse microglial cells by repeated LPS injection can cause epigenetic changes in these cells for up to six months [18]. This suggests that the baseline level of inflammation may increase upon repetitive inflammatory stimuli, potentially the cause of microglial priming. Such cumulative and long-lasting changes in the equilibrium of inflammatory mediators worsen the ability of microglia to perform basic physiological functions and are likely a contributing factor in neurodegenerative processes. For instance, young microglia can more efficiently phagocytose disease-related proteins, such as $A \beta[19]$ and $\alpha$-synuclein [20], than aged microglia. Likewise, it has been shown that aged microglia have impaired motility, surveillance, and phagocytosis responses to demyelinating lesions [21], in part due to reduced lysosomal function [22]. Taken altogether, these studies suggest that the susceptibility of different brain regions to AD may be linked to the overstimulation of immune-related signals during aging and the detrimental impact of these cascades in the functionality of the distinct populations of microglia present in each brain region.

\section{The opening of the blood-brain barrier during aging}

Another characteristic of aging with relevance for $A D$ is the increased permeability of the BBB to immune cells and molecules from peripheral tissues. Loss of $\mathrm{BBB}$ integrity seems to occur before hippocampal atrophy [23, 24] and cognitive impairment [25], suggesting that this breakdown precedes the neurodegenerative process in $\mathrm{AD}$. This evidence also indicates that peripheral activation of the immune system can contribute to the impairment in brain function and neurodegenerative processes that occur in $\mathrm{AD}$ [26]. Interestingly, an association has recently been made between midlife inflammation and late-life brain volume. Compared to individuals with no elevated midlife inflammatory markers, individuals with elevations in 3 or more markers had, on average, $5 \%$ smaller hippocampal and AD signature region volumes [24].

In healthy individuals, the cellular components of the neurovascular unit, including endothelial cells, pericytes and astrocytes, orchestrate the formation of tight junctions in endothelial cells in response to inflammatory signals to limit the infiltration of cells and molecules from the periphery. A secondary protective mechanism can also be triggered in astrocytes, which upon opening of endothelial tight junctions can regulate leukocyte and humoral transit by forming tight junctions of their own at the glia limitans of the BBB. Inhibiting the formation of this inducible astrocytic barrier increases disease severity in mouse models of neuroinflammation [27]. Therefore, a possible mechanism for the impairment in the $\mathrm{BBB}$ function is the immune-related senescence of its cellular components.

Endothelial cells, pericytes and astrocytes at the BBB are particularly vulnerable to the effects of aging and chronic stimulation by inflammatory mediators (Fig. 3). During aging, mouse brain endothelial cells express higher levels of TNF- $\alpha$ and decreased expression of the tight junction proteins occludin-1 and zonula occludens1 , which correlates with increased peripheral inflammation [28]. Aging and, more aggressively, AD also trigger damage to pericytes as demonstrated by the increased levels of platelet-derived growth factor receptor- $\beta$ observed in mouse models [23]. Although the mechanism inducing pericyte injury is still unknown, Bell and colleagues have shown that the age-dependent vascular damage in pericyte-deficient mice precedes neuronal degenerative changes, learning and memory impairment, and the neuroinflammatory response [29].

In astrocytes, transcriptome analysis has revealed that aging induces an upregulation of several immune-related genes [30]. An age-dependent change in astrocyte phenotype was identified by comparing gene expression in astrocytes from 10-week- and 2-year-old mice using RNAseq. This study demonstrated that astrocytes from healthy 2-year-old mice expressed genetic markers which correspond to the activated A1 phenotype, including C4a, C3, Serpina3n, and Cxcl10 [31]. Mechanistically, it has been shown that IL-1 $\beta$ suppresses the astrocytic expression of sonic hedgehog [32], a protein that protects the BBB by 
upregulating tight junction proteins in capillary endothelial cells [33]. IL-1 $\beta$ also increases the production of pro-inflammatory chemokines such as CCL2, CCL20, and CXCL2 by astrocytes, which induce immune cell migration from the periphery, and exacerbate BBB disruption and neuroinflammation [32]. Hence, an excessive pro-inflammatory phenotype significantly disrupts the protective role of astrocytes in maintaining BBB integrity.

Inflammation and aging are therefore closely linked with studies suggesting that low levels of inflammation correlate better with healthy brain function [24] and longevity [34]. Considering that most cells in the brain, including astrocytes [35] and microglia [36], have a long life-span, it is plausible that the build-up and overstimulation of inflammatory signals trigger multiple cumulative molecular modifications (e.g., telomere shortening, DNA damage, epigenetic modifications, lysosomal dysregulation) that eventually contribute to cellular senescence and loss of function. This idea is, at least in part, supported by a repopulation study in a mouse model of neurodegeneration, which demonstrated that, following pharmacological-induced cell depletion, the microglia that repopulated the brain displayed the morphological phenotype of young cells. Remarkably, the animals also showed significant improvement in brain functions [37]. Whether cell repopulation methods can reset the molecular signatures of immunosenescence is still unknown. Additional studies are needed to clarify the underlying cellular and molecular mechanisms related to the immune dysregulation that occur during aging which divert individuals from the relatively benign process of normal brain aging to the pathological processes associated with AD.

\section{The production of $A \beta$ as a physiological component of immune responses}

Accumulation of $A \beta$ is without doubt one of the major triggers of neurodegeneration in AD. Evidence suggests, however, that $\mathrm{A} \beta$ acts as a physiological trigger of pro-inflammatory responses during healthy aging and that its build-up results from age-related defects in the immune signals that control the molecular mechanisms involved in the production, degradation and clearance of this peptide. At picomolar to nanomolar concentrations, A $\beta$ modulates synaptogenesis, axonal growth and guidance, synaptic plasticity, oxidative stress, learning, and memory [38]. Moreover, at higher concentrations, $A \beta$ binds to inflammatory receptors (i.e., TLR2, TLR4, RAGE) [39-41], activates immune-related transcriptional factors (i.e., NF- $\mathrm{B}$ ) $[42,43]$, produces inflammatory mediators (i.e., TNF$\alpha$, COX-2, iNOS) $[42,44]$, and exerts potent antimicrobial activity [45], indicating that it is upregulated as part of the physiological acute innate immunity.
As the synthesis of $A \beta$ is dependent upon sequential $\beta$-secretase-1 (BACE1) and $\gamma$-secretase cleavage of amyloid precursor protein (APP), any factor which influences the levels of these proteins could potentially contribute to the accumulation of $A \beta$ (Fig. 1). Importantly, responsive sites for immune-related transcriptional factors which are commonly over-activated during aging and $A D$, including NF- $k B$, peroxisome proliferator-activated receptor- $\gamma$ (PPAR- $\gamma$ ), and STAT-1, have been described in the regulatory promoter region of the genes controlling the expression of APP [46], BACE1 [47-49], and proteins of the $\gamma$-secretase complex [50]. Bourne and colleagues have proposed that $B A C E 1$ transcription is repressed by $\mathrm{NF}-\mathrm{\kappa B}$ in neurons but activated in reactive astrocytes [47]. Although neurons account for most BACE1-mediated $\mathrm{A} \beta$ synthesis in $\mathrm{AD}$, it has been demonstrated that inflammatory mediators, such as IFN- $\gamma$, TNF- $\alpha$, and IL- $1 \beta$, induce the expression of BACE1 and the release of $A \beta$ in astrocytes, suggesting that these cells also contribute to the amyloidosis in $\mathrm{AD}[48,51]$. Moreover, He and colleagues have shown that genetic deletion of the TNF type-1 death receptor (TNFR1) in the APP23 mouse model leads to reduced NF- $\mathrm{kB}-$ mediated $B A C E 1$ expression, which is associated with lower $\mathrm{A} \beta$ levels and improved learning and memory [52]. The brain steady-state levels of BACE1 and A $\beta$ are also increased by the inflammatory enzyme 12/15-LOX [53]. The mechanism whereby 12/15-LOX controls BACE1 has not been elucidated; however, this enzyme modulates the levels of free fatty acids and eicosanoids that are known to regulate PPAR- $\gamma$ activity during inflammatory conditions [54]. Notably, PPAR- $\gamma$ acts as a suppressor of BACE1 expression [55]. Another member of the LOX family, 5-LOX, has also been shown to activate $\gamma$-secretase and induce $A \beta$ production, and levels of 5-LOX are increased in the brain during aging [56]. The relevance of the immune-related signals in the regulation of distinct components of the amyloidogenic cascade reinforce the idea of $A \beta$ as a mediator of the innate immune system. Likewise, these studies indicate that chronic inflammation is a potential contributor to the overproduction of $\mathrm{A} \beta$ in $\mathrm{AD}$. However, whether the age-dependent increase of inflammation can trigger the excessive production of $A \beta$ on its own to promote the onset of $A D$ requires further investigation.

\section{The proteases involved in the proteolysis of $A \beta$ are also linked to inflammation}

As for any major inflammatory cascade, many physiological cellular processes are in place to regulate the availability of $A \beta$ in the brain. For instance, neurons, microglia, and astrocytes produce the protease neprilysin to counter-regulate the increase in $A \beta$ levels. Although the participation of neprilysin in the brain immune response has not been explored, data from peripheral 
models indicate that it is an important component in the resolution of responses involving other inflammatory peptides. Genetic deletion of neprilysin promotes spontaneous inflammatory edema that is caused by diminished degradation of the pro-inflammatory neuropeptides substance $\mathrm{P}$ and bradykinin [57]. Blockage of neprilysin activity also exacerbates colitis [58], ileitis [59], and dermatitis [60], and recombinant neprilysin ameliorates inflammation [58]. Other proteases, including insulin-degrading enzyme (IDE) and matrix metalloproteinases (MMPs), are also produced upon activation of glial cells to neutralize $A \beta$. Kong and colleagues have shown that $A \beta$-induced IDE upregulation is mediated by the activation of $\beta_{2}$-adrenergic receptors in microglia [61], whereas this process is regulated by the low-density lipoprotein receptor-related protein-1 (LRP-1) in astrocytes [62]. IDE activity has also been linked to the degradation of the inflammatory chemokine macrophage inflammatory protein-1 in microglia [63]. In addition, astrocytic LRP-1 regulates the levels of MMP-2 and MMP-9 in response to $A \beta$, and inhibition of LRP-1, MMP-2 and MMP-9 in these cells results in accelerated $A \beta$ accumulation in the APP/PS1 mouse model of AD [62]. The appropriate activation of these degrading enzymes is therefore required for the resolution of $A \beta$ mediated immune responses and the prevention of chronic inflammation. Importantly, the overall brain activity of neprilysin and IDE are reduced during aging and $\mathrm{AD}[64,65]$. On the other hand, MMP-9 seems to be overproduced in response to $A \beta$, thereby contributing to the damage and leakage of the BBB [66].

\section{The immune-related clearance mechanisms for $A \beta$} Other cellular mechanisms that terminate $A \beta$ responses include clearance through phagocytosis and intracellular degradation, and transcytosis across the $\mathrm{BBB}$. These processes involve the binding of $\mathrm{A} \beta$ to transmembrane proteins such as LRP-1 and members of the ATP-binding cassette (ABC) transporter family. LRP-1 is an endocytic and cell-signaling receptor, and is important for the uptake of $\mathrm{A} \beta$ by astrocytes [62], neurons [67], and endothelial cells [68]. Moreover, during immune responses, LRP-1 expressed in macrophages and microglia acts as a scavenger receptor, removing debris, and necrotic and apoptotic cells [69]. The stimulation of this receptor also regulates inflammatory pathways in immune cells [70]. LRP-1 agonists suppress the expression of pro-inflammatory mediators, whereas its antagonists increase the expression of pro-inflammatory signals through the activation of c-Jun N-terminal kinase and NF- $\mathrm{B}[71,72]$. Therefore, activation of LRP-1 in microglia keeps these cells in an anti-inflammatory and neuroprotective status during inflammatory responses. Studies in human aged and AD subjects indicate that brain LRP-1 expression decreases and inversely correlates with the age of onset of AD [73]. It has also been reported that LRP-1 expression is reduced in the microvasculature of the $\mathrm{BBB}$ in aged rats [74]. This decline in LRP-1 levels might be another contributing factor to the overall increase in inflammation and $A \beta$ accumulation in the brain during the aging process.

ABCA1, ABCA7, and ABCB1 (also known as Pglycoprotein) are members of the $A B C$ family of transporters that are important for the clearance of $A \beta$, and hence, their loss of function results in the accumulation of plaques in the brain. ABCA7 is particularly relevant, as recent studies have shown that loss-offunction polymorphisms at its gene increase the risk for late- [75] and early-onset AD [76]. These transporters use the binding and hydrolysis of ATP to power the translocation of several substrates ranging from ions to macromolecules across membranes. For this reason, their normal physiological activity is required to maintain the healthy balance of mediators in the brain. Accordingly, Karasinska and colleagues have shown that acute LPS induces augmented brain pro-inflammatory response in mice lacking the $A B C A 1$ gene, suggesting that this protein participates in the resolution of immune responses by facilitating the clearance of inflammatory mediators [77]. Moreover, the expression of $\mathrm{ABC}$ transporters in immune cells contributes directly to phagocytosis. ABCA7-mediated activation of extracellular signal-regulated kinase (ERK) enhances the phagocytosis of apoptotic cells and the complement protein $\mathrm{C} 1 \mathrm{q}$ by macrophages [78]. Similarly, stimulation of ABCA1 results in the upregulation of the phagocytic proteins multiple epidermal growth factor-like domains 10 (MEGF10) and engulfment adapter PTB domain containing 1 (GULP1) in reactive astrocytes, which is important for the engulfment of debris during pathological processes [79]. ABCA7 also participates in the phagocytosis of $A \beta$ by microglia [80]. Interestingly, the overall expression levels of ABCA1 and ABCA7 are increased in AD $[81,82]$, indicating that their function is impaired in the diseased brain. Additional studies are needed to elucidate whether excessive and chronic inflammation can obstruct the activity of these transporters, causing a decline in $\mathrm{A} \beta$ clearance from the brain.

\section{Microglial phagocytosis decreases during aging}

As the major phagocytic cells in the brain, microglia have a central role in the clearance of $A \beta$. However, the efficacy of this removal diminishes during aging, and particularly in $\operatorname{AD}[19,83]$. Despite their inability to clear $\mathrm{A} \beta$, microglia continue releasing pro-inflammatory 
mediators to further stimulate the immune response [84], thereby creating a vicious cycle which leads to the build-up of activated immune cells, inflammatory mediators, and $\mathrm{A} \beta$. This process can be reversed by blocking $A \beta$ synthesis [85], and it is partially caused by the senescence of microglia [86]. Microglia from old APP/PS1 mice exhibit lower expression of the $\mathrm{A} \beta$-binding scavenger receptors scavenger receptor A (SRA), CD36, and receptor for RAGE than observed in cells from young mice. In contrast, these microglia express higher levels of the pro-inflammatory cytokines IL- $1 \beta$ and TNF- $\alpha$, suggesting that there is an inverse correlation between pro-inflammatory cytokine production and $\mathrm{A} \beta$ clearance. This idea is supported by in vitro studies in which treatment of microglia with TNF- $\alpha$ resulted in reduced SRA and CD36 expression, and A $\beta$ uptake [83]. In AD mouse models, microglia also display substantial impairment in calcium signaling [87] and beclin-1-mediated recycling of the phagocytic receptors CD36 and Trem2 [88], which are linked to poor $A \beta$ internalization. Based on longitudinal human brain imaging studies, Fan and colleagues have postulated that the status of microglia activation shifts from an early protective phenotype to a late harmful phenotype during the progression of $\mathrm{AD}$ [89]. This change in the overall microglial phenotype could be associated with the chronic activation of distinct populations of microglia, which are either $\mathrm{CX} 3 \mathrm{CR} 1^{+}$or Trem $2^{+}$and release inflammatory mediators or perform $\mathrm{A} \beta$ phagocytosis, respectively [90].

Although strong evidence indicates that aging impairs microglial activity, our understanding of the complex relationship between microglial senescence, $A \beta$, and $A D$ is still incomplete, as some studies have shown that microglial phagocytic activity towards $A \beta$ might not necessarily relate to changes in neurotoxicity and cognition. Investigations using the J20 APP mouse model have revealed that inhibition of microglial phagocytic activity by minocycline before $\mathrm{A} \beta$ accumulation results in increased amyloid plaque load, reduced inflammation, and improved cognitive performance, indicating that chronic inflammation can disrupt neuronal function independently of $A \beta$. However, when microglial inhibition was performed after $A \beta$ deposition had begun, inflammation was suppressed by minocycline with no effect on plaque load or improvement in cognitive performance [91]. Adding to the complexity of the inflammation to $\mathrm{AD}$ network, pharmacological or genetic depletion of microglia following robust $A \beta$ accumulation does not change the plaque levels but does rescue dendritic spine loss, prevent neuronal loss, and improve cognitive performance [92-95].

\section{The complexity of pro- and anti-inflammatory timing} Considering the strong evidence linking inflammation to the accumulation of $\mathrm{A} \beta$ in $\mathrm{AD}$, many research groups have been using loss- and gain-of-function approaches to identify the role and potential therapeutic value of specific mediators involved in the activation and resolution phases of inflammation. However, this has not proven to be a simple task, as recent studies have reported opposite neuropathological effects by manipulating pro- and anti-inflammatory signals in models of $A \beta$ pathology. For example, genetic deletion of CX3CR1 in AD mouse models changes the inflammatory milieu, resulting in higher microglia-mediated $A \beta$ phagocytosis [96] and reduced neuronal loss [97], suggesting that modulating the production of inflammatory signals is beneficial in AD. Similarly, genetic deletion of the inflammatory enzymes caspase-1 or NLR family pyrin domain containing 3 (NLRP3), which are involved in the synthesis of IL-1 $\beta$, improves clearance of $A \beta$ by microglia and cognitive performance in AD mice [98]. $\mathrm{Fu}$ and colleagues have shown that APP/PS1 mice treated with the cytokine IL-33 present lower levels of pro-inflammatory gene expression (i.e., $I L-1 \beta, I L-6$, $N L R P 3)$ in association with reduced $\mathrm{A} \beta$ load, increased magnitude of long-term potentiation (LTP) at Schaffer collateral-CA1 synapses, and improved cognitive function [99]. Blockage of mediators of the complement cascade, including C1q [100], C3 [101, 102], and C5a [103], also confers neuroprotective effects in mouse models of $\mathrm{AD}$. Moreover, deficiency of IkB kinase $\beta$, which activates NF- $\kappa B$, in microglia reduces inflammatory activation and $A \beta$ load in the brain of TgCRND8APP mice, effects which are associated with a reduction in cognitive deficits and preservation of synaptic structural proteins [104]. Overall, these studies suggest that blockage of pro-inflammatory responses is beneficial in AD. However, the integration between inflammation and $\mathrm{AD}$ is not so simple, as it has been demonstrated that stimulation of pro-inflammatory TLR4 with monophosphoryl lipid A (MLA) results in $A \beta$ phagocytosis by microglia in vitro, as well as a decrease in $A \beta$ load and cognitive impairment in the APP/PS1 mouse model [105]. Interestingly, although MLA is at least 100-fold less pyrogenic than the gram-negative bacterial cell wall constituent LPS, it maintains many of the immunomodulatory properties of LPS [106]. Based on this evidence Michaud and colleagues have suggested that the age-related defects in microglia can be overcome with a pro-phagocytic, yet mildly pro-inflammatory, phenotype leading to the improved clearance of $A \beta$ [105].

Targeting of anti-inflammatory and pro-resolution mediators has also produced mixed results, with the activation of IL-10 anti-inflammatory signaling in AD mouse models resulting in impairment in $A \beta$ phagocytosis and exacerbated AD neuropathology [107, 108]. On the other hand, stimulation of anti-inflammatory $\mathrm{LXA}_{4}$ $[109,110]$ or prostaglandin EP4 receptor (EP4) [111] 
signaling facilitates microglia-mediated $A \beta$ clearance and reduces AD-like pathology in mice. Notably, whereas IL-10 is increased [112], the levels of $\mathrm{LXA}_{4}$ [113] and EP4 [111] are reduced in human AD, indicating that targeting missing inflammatory mediators may be a better approach to restore the balance between pro- and antiinflammatory signals in the immune responses during aging and $\mathrm{AD}$.

Taken altogether, these studies illustrate the complexity of targeting distinct inflammatory mediators in $\mathrm{AD}$, but also clearly demonstrate that the phagocytic activity of microglia is highly important in the clearance of $A \beta$ deposits. Consequently, one of the current challenges in the field is to identify the underlying molecular mechanisms that regulate the phenotype of microglia or distinct microglial populations in order to develop strategies that stimulate the protective phagocytic phenotype while inhibiting the detrimental pro-inflammatory phenotype.

\section{Chronic inflammation causes tau phosphorylation and worsens pathology}

Neurons express many inflammatory receptors and molecules, including complement, MHC-I, TNFR1, IL-1R, and TLRs, allowing them to interact directly with microglia [114]. Inflammatory signals can consequently directly activate neuronal protein kinases and phosphatases, such as cyclin-dependent kinase 5 (CDK5), glycogen synthase kinase-3 $\beta$ (GSK3 $\beta$ ), ERK, and protein phosphatase $2 \mathrm{~A}(\mathrm{PP} 2 \mathrm{~A})$, that regulate tau phosphorylation and neuronal microtubule assembly [115-118]. Although the physiological relevance of this regulation remains to be elucidated, growing evidence suggests that it might be important for the regulation of synaptic pruning, LTP, neurogenesis, and cognitive function mediated by the activation of immune-related cascades in neurons. Thus, not only does tau appear to have a role in the coordination of neuron-microglia communication during the physiological activation of immune cascades in the brain, but age-related chronic inflammation also has the potential to trigger the onset and progression of tau pathology in AD.

Although there has been extensive research into $A \beta$ and inflammation, the effects of inflammation on tau pathology and vice versa remain comparatively untouched. It seems clear, however, that chronic microglial activation and inflammation cause the propagation of pathological tau species and participate in tau-induced neurotoxicity [119-122]. With regards to how inflammation induces tau pathology, most studies have shown that chronic levels of inflammatory mediators exacerbate the activation of key protein kinases that control the phosphorylation levels at tau. Chronic release of TNF- $\alpha$ from microglia, for instance, has been shown to induce the aggregation of tau in neurons in vitro [123]. On the other hand, blockage of microglia with minocycline reduces the inflammatory response and propagation of tau pathology in the hTau mouse model [124]. Inhibition of inflammation by arginase- 1 overexpression, which counterbalances the activity of nitric oxide synthases, facilitates autophagy and decreases tau pathology in the rTg4510 mouse model of tauopathy [125]. Roe and colleagues have shown that systemic stimulation of TLR4 by LPS promotes acute GSK3 $\beta$ - and CDK5-dependent phosphorylation of endogenous murine tau. It has been suggested that this process may be important for stressinduced responses, as it can be blocked by the genetic deletion of corticotropin-releasing factor receptor [126]. Notably, genetic deletion of tau decreases the neurotoxicity and levels of inflammatory proteins IL-1 $\beta$ and neuron-derived alarmin caused by LPS in mice [121]. The authors of this study proposed that this phenomenon is likely associated with the indirect reduction of microglial activity due to the diminished production of pathological tau species. Brain stimulation of TLR4 in the rTg4510 mouse model also results in the activation of microglia and the phosphorylation of tau [127]. In the 3xTg-AD mouse model, which develops both $A \beta$ and tau pathologies, chronic treatment with LPS results in CDK5dependent tau phosphorylation without affecting $\mathrm{A} \beta$ levels in adult animals ( $\sim 6$ months of age). Tau phosphorylation is observed at Ser202/Thr205 and Thr231/Ser235, but not Ser396/Ser404, which are recognized by AT8, AT180, and PHD finger protein 1 (PHF-1) antibodies, respectively [115]. Interestingly, activation of TLR4 induces tau pathology more aggressively in older 3xTg-AD mice ( 12 months of age), indicating that aging increases the susceptibility of tau to inflammatory events. Aged 3xTg-AD mice chronically treated with LPS show tau phosphorylation at AT8, AT180 and PHF-1 epitopes, tau aggregation into NFTs and cognitive impairment, but no change in $A \beta$ plaque load. In these older animals, however, modulation of tau pathology by TLR4 is mostly mediated by GSK3 $\beta$ [128]. Although no mechanism has been proposed for this age-dependent effect, it is possible that the exacerbated accumulation of pathological forms of tau is caused by the impairment of its intracellular clearance mechanisms such as autophagy and proteasome [129].

\section{The diverging impact of inflammation on $A \beta$ and tau pathology}

Adding to the complex connection between inflammation and $\mathrm{AD}$ is the mounting evidence that inflammation can exert opposing effects on $A \beta$ and tau. It has been shown that activation of IL- $1 \beta$ signaling triggers the activation of kinases CDK5, GSK3 $\beta$, and p38 mitogen-activated protein kinase (p38-MAPK), resulting in tau 
hyperphosphorylation and cognitive impairment in the 3xTg-AD mouse model [130]. Mechanistically, aging seems to cause a decrease in the levels of the senescence-related protein sirtuin 1 in microglia. This results in excessive IL-1 $\beta$ production, which in turn causes tau pathology and cognitive deficits [131]. Overexpression of IL-1 $\beta$ in the $3 \mathrm{xTg}$ - AD mouse model, however, promotes opposing effects on the amyloid and tau pathologies by accelerating the accumulation of pathological forms of tau while reducing the overall levels of $A \beta$ plaques. Stimulation of IL-1 $\beta$ results in an increase in the number of activated microglia surrounding $A \beta$ plaques, but also promotes the activation of GSK3 $\beta$ and p38-MAPK, leading to a higher level of tau phosphorylation [132].

Additional studies have reinforced the idea that inflammation can have distinct effects on these two major AD pathological markers. For instance, as discussed above, CX3CR1 deficiency in mouse models of amyloidosis mitigates $\mathrm{A} \beta$ accumulation by altering microglial activation and promoting microglial phagocytosis $[96,133]$. On the other hand, blockage of CX3CR1 signaling increases IL-1 $\beta /$ p38-MAPK-mediated tau phosphorylation in the hTau model of tauopathy [117]. Genetic deletion of membrane-anchored CX3CL1, which acts as a CX3CR1 agonist, in the APP/PS1 mouse model also reduces $A \beta$ deposition through the increase in microglia-mediated phagocytosis while inducing neuronal tau phosphorylation [134].

Moreover, deletion of progranulin, which has been extensively associated with frontotemporal dementia [135], results in increased TYRO protein tyrosine kinase binding protein (TYROBP) signaling activation and microglial $A \beta$ phagocytosis in the APP/PS1 mouse model, whereas it increases tau pathology in human P301L tau-expressing mice [136]. These opposing immune signal-induced effects on $\mathrm{A} \beta$ and tau accumulation raise significant concerns regarding the clinical efficacy of therapies designed to inhibit or activate inflammation in $\mathrm{AD}$, particularly considering that tau levels better correlate with the cognitive deficits observed during the disease process [137]. Although challenging, developing strategies that can modulate the immune system by favoring $A \beta$ clearance while reducing the levels of inflammatory signals that drive tau pathology will likely produce better clinical outcomes.

\section{Chronic inflammation impairs cognition and synaptic plasticity}

Although learning and memory, synaptic plasticity, and inflammation are usually considered separately, there is convincing evidence that inflammatory pathways have a significant role in the development and maintenance of the health and plasticity of the central nervous system (CNS) and are not only activated during times of defense and disease. Physiologically, immune-related receptors such as MHC-I, TNFR1, and IL-1R participate in LTP and modulate learning and memory formation [114]. For example, neurons from MHC-I-knockout mice show increased synaptic plasticity, excitability, and LTP [138], which is increased in 12-month old mice [139], likely exerting this effect via modification of NMDAR and $\alpha$-amino-3hydorxy-5-methyl-4-isoxazolepropionic acid receptor (AMPAR) function and trafficking [140]. It has recently been shown that IL- $1 \beta$ directly suppresses hippocampal plasticity via neuron-specific mechanisms [141] and that increased pro-inflammatory IL-1 accessory protein signaling, specifically at the synapse, underlies the augmented vulnerability to IL- $1 \beta$-mediated cognitive impairment that occurs with age [142]. Moreover, immunerelated cascades contribute to plasticity through the regulation of microglia-mediated synaptic pruning. It has been shown that genetic depletion of microglia in CX3CR1 ${ }^{\mathrm{CreER} /+}-\mathrm{R} 26^{\mathrm{iDTR} /+}$ mice results in reduced synapse formation and memory deficits [143]. A similar effect was found in CX3CR1-knockout mice, in which neural connectivity was reduced together with a reduced behavioral tendency to prefer social interaction [144]. Mechanistically, synaptic pruning can be regulated by inflammatory signals, including the complement cascade factors $\mathrm{C} 1 \mathrm{q}$ C3R [145] and chemokines CX3CL1-CX3CR1 [146]. Hence, it is not surprising that excessive neuroinflammation can lead to direct impairment of cognitive function. During $\mathrm{AD}$, there is evidence that microglia cause a significant amount of synaptic loss, likely through dysfunctional synaptic pruning $[95,147]$. Furthermore, chronic neuroinflammation leads to the loss of synaptic-associated proteins, thereby causing neuronal damage [148]. Thus, chronic inflammation influences each of the three hallmarks of AD pathology: $A \beta$ accumulation, tau phosphorylation and cognitive decline associated with synaptic and neuronal loss.

\section{The genetic risk factors for AD are involved in the inflammatory response}

The ApoE isoforms and their relevance to inflammation

Apolipoprotein E (ApoE), the most prevalent genetic risk factor for late-onset $\mathrm{AD}$, is a polymorphic lipoprotein which mediates the transport and delivery of cholesterol and other lipids through cell surface ApoE receptors. Human ApoE exists in three isoforms in which polymorphisms are found in the receptor binding domain-ApoE4 (R112, R158), E3 (C112, R158), and E2 (C112, C158)-with ApoE4 conferring the highest risk for $\mathrm{AD}$. ApoE has a variety of roles in the CNS, including lipid homeostasis, repair of injured neurons, maintenance of synaptic-dendritic connections, and scavenging toxins including $A \beta$. Notably, 
ApoE is also an important modulator of immune responses, as evidenced by greater immune activation in mice lacking ApoE [149]. Studies in knockout mice have mostly demonstrated that ApoE has an anti-inflammatory effect, as seen in models of ischemia [150], traumatic brain injury (TBI) [151], and chemical-induced neuroinflammation [152].

In the brain, the inflammatory processes mediated by microglia and astrocytes are altered in an isoform-specific manner, with ApoE4 promoting the strongest pro-inflammatory effects $[153,154]$ and ApoE4 transgenic mice being more susceptible to inflammation than those expressing ApoE2 and ApoE3 [155-157]. Interestingly, studies in humans have shown that intravenous administration of LPS in ApoE3/ApoE4 patients produces higher hyperthermia and plasma TNF- $\alpha$ levels and earlier plasma IL-6 than in ApoE3/ApoE3 subjects [158]. Likewise, animals expressing ApoE4 show greater levels of pro-inflammatory cytokines and neurotoxicity in response to systemic [159] and central [160] LPS, than their ApoE3 counterparts. Together, these studies indicate that ApoE4 has lost its anti-inflammatory properties and inefficiently prevents the detrimental impact of inflammation. The mere expression of ApoE4 can therefore potentiate the immune activation associated with aging, eventually leading to neurodegenerative disease. Supporting this idea, studies in mice and humans have demonstrated that ApoE4 amplifies the pro-inflammatory innate immune response induced by $\mathrm{A} \beta$, resulting in a robust inflammatory phenotype that causes neuronal dysfunction $[156,161]$. In addition, antagonism of the liver X receptor in APP23 mice leads to increased microglial activation and phagocytosis of $A \beta$, effects not observed in the absence of ApoE, indicating that ApoE is essential for the microglial response to $A \beta$ [162]. Interestingly, $A p o E$ is also an endogenous ligand of TREM2 [163], and their interaction appears necessary to mediate the switch from a homeostatic to a neurodegenerative microglial phenotype after phagocytosis of apoptotic neurons, as observed in microglia associated with $A \beta$ plaques [164]. Whereas ApoE3 has an essential anti-inflammatory role in AD and other diseases, the balance between pro- and anti-inflammatory signaling is aberrantly altered for those carrying ApoE4 [154]. Although the reason for this is yet to be fully elucidated, the interaction between ApoE and TREM2 may shed some light on the different mechanisms caused by ApoE isoforms, with respect to inflammation.

\section{The TREM2 mutations that lead to changes in microglial phagocytosis and increased $A D$ risk}

TREM2 is a relatively new addition to the list of genes which are reported to be related to an increased risk of developing $\mathrm{AD}$, with a genome-wide association studies
(GWAS) in 2013 confirming that R47H TREM2 mutant is associated with $\mathrm{AD}$ [165] and specifically tau hyperphosphorylation [166]. Although the R47H mutation has the strongest association with $\mathrm{AD}$, patients have a significantly higher chance of mutation in their TREM2 exon 2 sequence than healthy controls. These mutations include Q33X, T66M and Y38C, which generally confer a loss of receptor function [165]. This finding is interesting given that TREM2 is necessary for microglial phagocytosis [167]. TREM2 acts with an adapter TYROBP (also known as DAP12) to detect stimuli, such as LPS and bacteria [168], and initiate phagocytic pathways within microglia via its immunoreceptor tyrosine-based activation motif [169]. Recently published research has also shown that TREM2 is a direct receptor for $A \beta$, inducing microglial depolarization and an increase in their pro-inflammatory response [170]. The TREM2-TYROBP complex has been shown to have both a pro- and anti-inflammatory role in the peripheral immune system; in dendritic cells, it has been demonstrated that TYR$O B P$ knockout can reduce pro-inflammatory chemokine production [171], and knockout of TREM2 can enhance the TLR response [172]. These two opposing findings indicate that the TREM2-TYROBP complex is a key, albeit complicated, player in the immune response, whereby the knockout of individual components may result in different effects. These data suggest that TREM2 subdues the activity of other inflammatory receptors, while TYROBP is responsible for pro-inflammatory TREM2TYROBP signaling. Following proteolytic cleavage of TREM2 by a disintegrin and metalloproteinase (ADAM) proteases, extracellular soluble TREM2 (sTREM) activates microglia via the Akt-GSK3 $\beta$ pathway, leading to the activation of the NF- $\mathrm{kB}$ transcription factor and thus the transcription of pro-inflammatory cytokines through binding of microglial cell surface receptors [173]. Interestingly, the level of sTREM is elevated in the cerebrospinal fluid and plasma in neuroinflammatory diseases including $\mathrm{AD}$, correlating with overall patient inflammation [174, 175].

As microglial phagocytosis has been shown to significantly reduce the plaque load observed in mouse models of $\mathrm{AD}$, researchers investigated whether the TREM2 mutations associated with $\mathrm{AD}$ conferred a loss of receptor function, finding that the rare TREM2 variants caused impairment of phagocytosis [176]. The missense mutation $\mathrm{R} 47 \mathrm{H}$ of TREM2 is associated with AD risk by dysregulating neuroinflammation and increasing AD pathology [165, 177]. Mazaheri and colleagues showed that TREM2 knockout reduced microglial reactivity and consequently blocked essential defense functions of microglia during disease progression [178]. They further showed that TREM2 knockout mice had impaired microglial migration and process outgrowth, likely due to dysregulation of 
genes associated with chemotactic motility. Recently, a TREM $2^{\mathrm{R} 47 \mathrm{H}}$ mouse model has been produced, which displays abnormal macrophage apoptosis and necrosis [179]. Interestingly, these mice also failed to mount a pro-inflammatory response to challenges, including LPS, demonstrating a failure to produce pro-inflammatory cytokines. This further suggests that the $\mathrm{R} 47 \mathrm{H}$ mutation of TREM2 renders it inactive. In support of these findings, it has also been shown that the uptake of ApoE-A $\beta$ complexes is reduced in macrophages from human subjects carrying the R47H TREM2 variant [180]; however, whether ApoE isoforms affect TREM2-mediated neuroinflammation response in an isoform-specific manner in the pathogenesis of $\mathrm{AD}$ is still unknown.

Several studies over the past 3 years have investigated the relationship between $A \beta$ and TREM2 activity by overexpressing TREM2 or using TREM2 knock out strategies. These studies have reported varying effects, depending on the mouse model and age of the animals, but may suggest similar trends. For example, in the absence of TREM2, mouse models of amyloidosis show that $A \beta$ plaque load is decreased in younger mice, but increased in older animals [181]. Jay and colleagues suggest that this may be due to the changes in the microglial phenotype that occur during aging, perhaps due to the acquired senescence of microglia towards the later stages of AD [181]. When TREM2 was overexpressed via intracerebral lentiviral particle injection into either the hippocampus or cortex of 7-month-old APP/PS1 mice, a decrease in A $\beta$ plaque load was observed in both brain regions 2 months later [182]. This translated to improved performance in the Morris water maze. These findings suggest that TREM2 is integral to controlling the $A \beta$ plaque load by initiating a microglial phagocytic response to the aberrant protein accumulation. Interestingly, this effect appears to depend on the state of disease progression. APP/PS1-TYROBP ${ }^{-/-}$ mice display a reduction in the prevalence of $A \beta$ oligomers and microglial activation compared to APP/

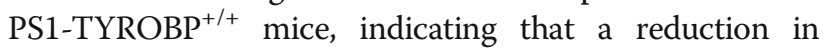
TREM2 signaling leads to beneficial effects in an AD mouse model [183]. Kim and colleagues recently found that TREM2 knockout was sufficient to cause the formation of endogenous murine $A \beta$ plaques, and showed that TREM2 promotes the phagocytosis of $A \beta$ by upregulating CD36 in microglia [184]. These data make it clear that TREM2 has a significant role in the clearance of abnormal protein deposits, although the mechanism by which this occurs has yet to be identified. TREM2 appears to be essential for the recognition of $A \beta$ by microglia, but also counteracts the TLR-mediated inflammatory response [185], thereby having a pro-phagocytosis, but anti-inflammatory effect on microglia. In addition to the different ages and AD models used by various researchers, this may also account for the variations observed in the outcomes reported using TREM2-deficient AD mouse models.

More recently, tau models of AD were compared in the presence or absence of TREM2. Initially, knockout of TREM2 in the hTau model was shown to increase tau pathology, as well as increasing neurodegeneration and cognitive decline [186]. In contrast, a recent paper by Leyns and colleagues reported that neurodegeneration is reduced in the PS19-TREM2 ${ }^{-/-}$mouse model, compared to PS19-TREM2 ${ }^{+/+}$animals [187]. The authors found that there was reduced microgliosis and astrogliosis in PS19-TREM2 ${ }^{-/-}$mice, indicating that the reduced inflammatory activity may reduce neuronal damage. Although these results appear to be contradictory, it is worth noting that the PS19 model of tau pathology is more severe and the microglia may therefore already be in an overactive state. Reducing microglial phagocytosis in PS19-TREM2 ${ }^{-/-}$mice may lead to a reduction in neuronal damage, while causing an increase in inflammation in mice with less severe pathology via TLR activation, as observed in mouse models of $A \beta$ with TREM2 deficiency. Microglial-neuronal co-culture has also recently been used to identify the effects of TREM2 during tau pathology, revealing that the tau pathology in neurons is reduced in the presence of microglial TREM2 [188]. Jiang and colleagues suggest that this is due to suppression of the microglial inflammatory response by TREM2, as its presence leads to a reduction in the transcription of inflammatory mediators. At this stage, the effects of TREM2 on tau pathology are still becoming clear and may differ depending on the pathology and age of the mouse model used. Although it seems that microglia expressing TREM2 are important for the removal of pathological tau species, it is also possible that over-activation of these cells, and the resultant chronic inflammation, have a detrimental effect on tau function.

\section{The CD33 SNPs confer differing risks for AD}

CD33, also known as Siglec-3, is a type-I transmembrane protein from the sialic-acid-binding immunoglobulin- like lectin family, which is known to mediate intercellular communication and downregulate immune cell function. CD33 expression is also present on cells with phagocytic activity, such as macrophages, monocytes, dendritic cells, and microglia, and acts as an inhibitory mediator [189]. Following CD33 activation on human monocytes, PI3 kinase- and p38-MAPK-mediated inhibitory signal transduction has been reported to impair inflammatory-cytokine synthesis, leading to decreased levels of TNF- $\alpha$, IL- 8 , and IL- $1 \beta$ [190]. More recently, downregulation of CD33 has also 
been associated with increased production of TNF- $\alpha$ [191].

CD33 was initially implicated in AD pathogenesis by GWAS in four well-characterized samples of AD families, where several risk single nucleotide polymorphisms (SNPs) were identified, with the highest risk being associated with rs3826656 [192]. GWAS has also shown that increased expression of CD33 is associated with cognitive decline in dementia patients and that SNP rs3865444 is upregulated in AD patient brains [193]. An increase in the expression of rs3865444 has also been reported to positively correlate with $A \beta$ pathology upon patient autopsy [194]. Interestingly, a minor allele of rs3865444 (A) was found to be AD-protective [195], compared to the significant AD risk conferred by allele rs3865444 (C) [196]. Research into the mechanism behind these differences revealed that each allele altered the splicing of rs3865444 SNP mRNA, leading to increased expression of the rs3865444 (C) allele and thus increased CD33 expression [197], whereas the rs3865444 (A) allele led to translation of an inactive isoform of CD33 [198, 199]. One of these studies [198] also described the effects of CD33-knockout in the APP/PS1 mouse model, in demonstrating that APP/ $\mathrm{PS}_{-\mathrm{CD} 33^{-/}}$mice displayed a significant decrease in amyloid plaque burden, without altering APP processing, compared to APP/PS1-CD33 ${ }^{+/+}$controls. CD33 was also shown to be primarily expressed by microglia, suggesting that it prevents the clearance of $A \beta$, thereby contributing to the risk of $\mathrm{AD}$ via failure of microglial phagocytic activity.

Interestingly, there appears to be a relationship between the effects of CD33 and TREM2 during AD. The AD-risk CD33 rs3865444 (C) allele is associated with increased TREM2 surface expression in monocytes, compared to rs3865444 (A), whereas blocking CD33 signaling leads to a reduction in TREM2 surface expression [200]. Measuring the levels of TREM2 and CD33 expressed by microglia at different time points following $A \beta$ treatment revealed that TREM2 is expressed at a higher level initially, correlating with increased microglial phagocytosis [201]. Later time points in these experiments revealed that TREM2 expression subsequently decreases, whereas CD33 expression increases in association with diminished phagocytic capabilities. In addition, CD33 was shown to be downregulated in APP/PS1-TYROBP ${ }^{-/-}$mice, which had reduced microglial reactivity to $A \beta$ and performed better in spatial learning tests [183]. Overall, this evidence suggests that the receptors CD33 and TREM2 may work as an on-off switch for microglial phagocytosis in healthy individuals, a process which is altered during AD where gene expression is skewed towards heightened microglial reactivity and a pro-inflammatory response.

\section{The metabolic disorders and AD}

Aging is also associated with other chronic disorders, including metabolic syndromes such as diabetes, obesity, and hypertension, which also appear to contribute to overall inflammation and the exacerbation of AD. Thus, in many cases, it is difficult to study the contribution of aging to $\mathrm{AD}$ in isolation from other age-dependent disorders. Type 2 diabetes mellitus (T2DM), for instance, has been shown to increase the risk of developing $\mathrm{AD}$, as well as contributing to the worsening of neurological symptoms [202]. Epidemiological studies have reported that insulin resistance and T2DM elevate the risk of mild cognitive impairment progressing to AD [203, 204]. Failure of the insulin receptor in the synaptosomes of a diabetic mouse model $(\mathrm{db} / \mathrm{db})$ leads to accelerated $A \beta$ aggregation in vitro [205], and similarly, excess peripheral insulin has been shown to increase hippocampal $A \beta$ accumulation in APP/PS1 mice, an effect which is exacerbated by age [206]. Overall, obesity and T2DM exacerbate $\mathrm{A} \beta$ and tau pathologies, accelerating cognitive decline and worsening neuroinflammation in both middle age and old mice. Another interesting link between insulin resistance and $A \beta$ accumulation is IDE, which is responsible for not only the degradation of excess insulin, but also the degradation of $A \beta$, as discussed earlier. Farris and colleagues have suggested that excessive insulin circulation during insulin resistance may lead to reduced degradation of $A \beta$ [207]. Insulin resistance has also been found to alter tau dephosphorylation via inhibition of adenosine monophosphate-activated kinase [208], and tau hyperphosphorylation has been observed in the hippocampi of the fa/fa rat model of obesity, with the extent of phosphorylation being increased in aged rats [209]. Interestingly, the relationship between T2DM and $\mathrm{AD}$ does not appear to be one sided, with intrahippocampal injection of $A \beta$ leading to decreased insulin sensitivity in male rats [210]. The ApoE4 genotype has also been implicated in the effects of obesity on $\mathrm{AD}$, whereby a high-fat diet increased $A \beta$ pathology in the familial $A D$ (FAD) mouse model expressing ApoE4 but not ApoE3 [211], and was shown to worsen the cognitive decline associated with insulin resistance [212].

Although primarily associated with metabolism, obesity, hypertension, and T2DM have also been shown to lead to increased peripheral inflammation. Adipose tissue has been reported to produce pro-inflammatory cytokines [213], particularly TNF- $\alpha$, which can impair insulin signaling, thereby increasing the risk of insulin resistance [214]. The excessive release of pro-inflammatory mediators, including TNF- $\alpha$ and IL- 6 , is likely due to the accumulation of macrophages in the adipose tissue of obese individuals [215]. Pro-inflammatory cytokine release has also been associated with a high-fat diet [216]. In patients with both T2DM and hypertension, the plasma 
levels of IL-6 were significantly increased [217], suggesting an inflammatory link within disorders classified as metabolic syndrome. Adipose tissue inflammation occurs prior to hepatic tissue inflammation in insulin-resistant, obese C57BL/6 mice, likely indicating that it contributes to the development of insulin resistance [218], with similar results being reported in CD-1 mice [219]. Further, in human patients with T2DM, the NLRP3 inflammasome is activated, leading to the upregulation of IL-1 $\beta$ and IL-18 [220], with a receptor agonist of the latter currently being tested in clinical trials for the treatment of T2DM [221]. Likewise, the NLRP3 inflammasome is also activated during hypertension [222]. Interestingly, the gene expression profiles of cultured peripheral immune cells have been shown to change in response to high glucose conditions and T2DM, affecting neutrophil movement [223], increasing monocyte activation markers [224] and increasing monocytic TLR expression [225]. Monocytes and neutrophils from T2DM patients have also been found to have increased pro-inflammatory cytokine and TLR expression, with the extent of this effect changing based on glycemic control [226]. Inflammatory mediators also have a causative effect in insulin resistance, with TNF- $\alpha$ being found to increase phosphorylation of insulin receptor substrate-1, which leads to diminished insulin signaling [227]. In addition, IL-1 $\beta$, IL-6, and many other pro-inflammatory mediators have been implicated in defective insulin signaling, leading to insulin resistance and eventually T2DM [228-230]. Interestingly, Dhande and colleagues found that hypertension-protective stimulation of angiotensin receptor AT2 leads to anti-inflammatory IL-10 release, although the mechanism through which this occurs has yet to be determined [231].

In the brain, research has demonstrated that T2DM, a high-fat diet, and obesity cause cognitive decline and impairment, in both mouse models and human patients [232-235]. Hypertension has been shown to cause synaptic loss in wild-type mice [236], as has obesity in a rat model [237]. The same study also found that obesity caused phenotypic changes in the microglia of the rat prefrontal cortex, and led to cognitive decline [237]. Similar results have been reported in mice, where obesity activated microglia, causing excessive synaptic pruning and loss [238]. Overall, these data suggest that excessive inflammatory mediators produced by adipose tissue during metabolic syndrome affect the brain, stimulating microglia and causing synaptic pruning, and perhaps initiating the accumulation of $A \beta$. Although mechanistic studies are still necessary to directly link the changes in the immune system caused by metabolic disorders and $\mathrm{AD}$, these findings reinforce the complexity of the relationship between inflammation and genetic and lifestyle risks, which may act cumulatively to increase the risk of developing $\mathrm{AD}$.

\section{Acute damage to the brain triggers inflammation and increases $A D$ risk}

Epidemiological data point to TBI as a major risk factor for $\mathrm{AD}$, although a direct link with $\mathrm{AD}$ has been inconsistently reported [239]. A recent analysis of the literature found that the relationship between TBI and dementia in human patients is likely dependent on TBI severity and frequency, which may account for varying reports of correlation [240]. In humans, TBI was shown to cause increased production of soluble $A \beta$ in resected cortical tissue, and it was also reported that the ApoE genotype of the patient may alter their risk for $\mathrm{AD}$ in later life [241]. Further, in approximately 30\% of fatal TBI cases, $A \beta$ deposits were identified in the neocortex [242]. Johnson and colleagues also found $A \beta$ deposits at a greater density in the post-mortem brains of TBI patients than in non-injured controls, and demonstrated that tau NFTs were present in approximately one third of TBI patients' tissue [243]. A controlled cortical impactor was used to test this in a rat model, revealing increased activation of inflammatory cells, increased expression of APP and increased tau phosphorylation [244]. Conversely, it has also been proposed that the increase in APP following acute TBI is beneficial, with $\mathrm{APP}^{-1-}$ mice having worse behavioral outcomes than $\mathrm{APP}^{+/+}$controls [245], possibly due to the neuroprotective peptide secreted APP $\alpha$ [246, 247]. Although the upregulation of APP may be important for neuronal survival, it could also lead to the production of $A \beta$ in some cases of TBI. Overall, it appears that TBI worsens $A \beta$ and tau pathology, via increased neuroinflammation.

TBI generally involves both a primary and a secondary injury; the primary injury is caused by a mechanical force during the acquisition of the injury, while the secondary injury usually follows the disruption of the BBB, leading to brain swelling/edema, increased inflammation and hyperexcitability. Patient complications generally arise from the secondary injury, as a result of excessive neuronal loss. Microglia have been shown to activate within minutes of TBI in mouse models, resulting in positive survival outcomes in mice compared to those that could not mount a microglial response [248]. Activation of microglia stimulates the release of pro-inflammatory cytokines and chemokines, as well as danger-associated molecular pattern (DAMP) molecules, which signal cell death and further stimulate phagocytic microglia [249]. Damaged neurons have also been found to release pro-inflammatory signals during the primary injury [250]. During the secondary injury, increased levels of pro-inflammatory mediators (e.g., IL-1 $\beta$, IL-6, IL-8, TNF- $\alpha$ ) are associated with a poorer prognosis, increased intracranial pressure, and mortality in human patients [251]. In a rat model of repetitive mild TBI, IL- 6 and TNF- $\alpha$ were also 
expressed at higher levels than in rats modeling single mild TBI, indicating that repetitive injuries can cause chronic inflammation [252]. Interestingly, in rats where the more severe Feeney model of TBI was used, researchers found that, although IL-1 $\beta$ expression was initially upregulated following injury, IL-18 was chronically expressed [253]. This may indicate that IL-18 has a prolonged effect on TBI, perhaps related to the secondary injury and ongoing recruitment of peripheral inflammatory cells.

In addition to microglia, astrocytes are also responsible for regulating the inflammation associated with TBI and can modulate BBB permeability during injury. Astrocytes also express TLRs and are therefore able to react to inflammatory stimuli, leading to the release of pro-inflammatory mediators [254]. The activation of astrocytes can cause astrocyte swelling/edema, which poses a significant risk to the recovery of TBI patients following injury, and is regulated by the activation of astrocytic NF- $\mathrm{B}$ [255]. Despite this, reactive astrocytes are also integral to endothelial repair of the BBB following [256]. Astrocytes have long been associated with $\mathrm{BBB}$ health, with the interaction between astrocytes and endothelial cells being integral to its correct function, including its permeability to the influx of peripheral immune cells following TBI $[33,257]$. The increase in the pro-inflammatory cytokines TNF- $\alpha$ and IL- $1 \beta$ in the hours following TBI may be responsible for the increased permeability of the $\mathrm{BBB}$, initially in order to recruit immune cells. TNF- $\alpha$ has been shown to increase the permeability of endothelial monolayer cultures via actin remodeling in vitro $[258,259]$, and transgenic overexpression of IL-1 $\beta$ in mice was found to increase BBB permeability [260]. In addition, increased expression of chemokines and chemokine receptors following TBI, including CXCL2, CXCR2, CCL2, CXCR4, and chemokine-like factor 1 (CKLF1), has been shown to further permeabilize the BBB [261-264] and attract neutrophils $[265,266]$. This causes a significant influx of peripheral immune cells into the brain following TBI, which has been found to worsen edema and neuronal damage [267-269].

Together, these studies suggest that the timing of pro-inflammatory signaling may be the key to survival following injury or illness. The initial pro-inflammatory event is necessary to allow immune cells to clear infection or debris, but if prolonged, it can cause excessive damage and secondary diseases including AD. Although it is not entirely clear how TBI might initiate AD, it is worth noting that the ApoE4 allele is associated with both $\mathrm{AD}$ risk and increased severity of TBI [270], and may therefore also play a significant role in the risk that TBI poses in relation to AD. Interestingly, a link was also recently made between ApoE4, TBI, and tau phosphorylation. Cao and colleagues found that ApoE4 knock-in mice had significantly more phosphorylated tau following blast TBI than ApoE3 knock-in mice, via activation of GSK3 $\beta$ [271]. In addition, recent transcriptional profiling of ApoE4 and ApoE3 knock-in mice at 14 days post-TBI found significant upregulation in TREM2, TYROBP, C-type lectin domain containing 7A, Cd68, and CX3CR1 compared to the sham control [272]. Not only are these proteins related to phagocytosis, but they have also been investigated thoroughly with respect to $\mathrm{AD}$, where malfunction in TREM2 and Tyrobp proteins leads to increased AD risk. Out of 11 epidemiological reports published between 2005 and 2015, only two accounted for ApoE genotype [240], with one finding an additive effect of ApoE4 genotype and head injury in the risk of developing dementia [273], and the other reporting little evidence for a relationship between ApoE4 and dementia [274]. It is possible that AD is triggered by TBI in individuals who already carry an AD risk gene, which may explain conflicting literature if the genetic risks are not considered and also suggests that genetic and environmental risk factors could act cumulatively.

\section{The microbiota, inflammation, and AD}

Interest in the role that the gut microbiota plays in disease has increased in recent years, as evidence of its importance in maintaining the normal physiology and health of the host has grown. Bacteria, fungi, archaea, virus, and protozoa collectively form our gut microbiota, acting in a symbiotic manner beneficial to the host. Changes in the composition of this complex ecosystem, referred as dysbiosis, has been associated with aging and the development of inflammatory and CNS disorders, including $\mathrm{AD}$ [275]. An infectious origin of $\mathrm{AD}$ has long been postulated, with ethiological hypotheses suggesting chronic that infection with various bacteria, viruses, parasites, and fungi may contribute to AD. However it was only recently that researchers started to explore the role of the gut microbiome in the pathogenesis of AD.

Aging causes the degeneration of enteric nervous system, alterations in gastrointestinal motility, and perturbations in small intestinal permeability and the mucosal defense system. This degeneration may promote the development of gastrointestinal disease, affect the local and systemic inflammatory status, and deeply influence both the composition and function of the resident microbiota [276], reducing its diversity and stability [277, 278]. These changes lead to a progressive decline in immune function associated with a chronic pro-inflammatory response $[279,280]$. As previously discussed, immunosenescence also has severe consequences in the brain, such as BBB breakdown, and microglial hyper-activation and eventual senescence, which contribute to the development of AD [281]. Age-related changes in the gut microbiota 
have been shown to impact behavioral and cognitive functions in mice and support the relevance of the alteration in gut permeability and peripheral inflammation in mediating these effects [280]. An aged gut microbiota has also been shown to promote systemic immunosenescence when transferred to germ-free mice [282]. This suggests that the gut microbiota dysbiosis observed in the elderly could contribute to peripheral inflammation, therefore exacerbating neuroinflammation and $\mathrm{AD}$.

In addition to aging, there are many other factors that can affect gut microbiota populations. Changes in gut the microbiota can trigger an immune system response and the microbiome of patients with inflammatory diseases. For example, in multiple sclerosis patients, researchers found that specific species of gut bacteria were upregulated or downregulated and that microbiota transplants from patients to germ-free mice led to an autoimmune response, which was not observed with microbiota transplants from healthy controls [283]. Due to this tight cross-talk between the gut microbiota and the immune system, a wide variety of external factors which affect the former can ultimately affect systemic inflammation and promote disease progression. Thus, it is not surprising that most of the factors described as risks for $\mathrm{AD}$ also influence the gut microbiota, including obesity [284], diet [278], T2DM [285, 286], chronic stress $[287,288]$, and the use of antibiotics [289]. Interestingly, as the gut microbiota can be modified by diet, many of these effects were effectively restored and even prevented by treatment with probiotics [290, 291].

A recent study which compared the composition of the gut microbiome in participants with and without $\mathrm{AD}$ revealed that the gut microbiome of $\mathrm{AD}$ participants had decreased microbial richness and diversity [292]. This study reported that $\mathrm{AD}$ patients have a low abundance of Firmicutes and Bifidobacterium and a characteristic increase in the abundance of Bacteroidetes [292]. This difference in microbial diversity correlated with cerebrospinal fluid biomarkers of AD pathology [292]. Gut bacterial taxa in cognitively impaired elderly participants were studied, revealing that the abundance of the pro-inflammatory Escherichia/Shigella was increased, whereas anti-inflammatory $E$. rectale was reduced, which correlated with cognitive impairment and brain amyloidosis [293]. Studies of AD mouse models and germ-free mice supported the latter findings. The APP/PS1 mouse model showed a distinct microbial signature, with an increase in Rikenellaceae and decreased Allobaculum and Akkermansia [294]. Interestingly, reduced levels of Akkermansia in the gut microbiota is also associated with mouse models of obesity and T2DM [295], two potentially modifiable risk factors for AD. Researchers also found that young and old APP/PS1 mice raised under germ-free conditions had reduced cerebral $A \beta$ pathology when compared with control mice, together with reduced microgliosis [295]. Increased cerebral $A \beta$ pathology was observed following a microbiota transplant from conventionally raised APP/PS1 mice, whereas transplant from non-transgenic mice did not increase $A \beta$ levels to the same extent [295]. Germ-free-APP/PS1 mice exhibited increased expression of the $A \beta$-degrading enzymes IDE and neprilysin degrading enzyme compared to conventionally raised APP/PS1 mice, suggesting that the gut microbiota influences the clearance of $A \beta$ via degradation [294]. Data supporting this finding were obtained in APP/ PS1 mice following life-long antibiotic treatment, which induced dysbiosis [296]. Interestingly, elevated levels of APP were found not only in the brain but also in the different gut districts from the 5xFAD mouse model, and these changes were associated with a distinct fecal microbiota profile, indicating an increase in pro-inflammatory species (e.g., Clostridium leptum) [297]. Hence, these studies provide evidence that the diversity of gut microbiota can modulate host innate immunity mechanisms that impact amyloidosis, thereby affecting the progression of AD. The imbalances in gut microbiota composition together with the increased $\mathrm{BBB}$ permeability that occurs with age may lead to the translocation of microbes or microbial components from the gut to induce neuroinflammation [298]. In this regard, coincubation of A $\beta$ with LPS has been shown to potentiate $A \beta$ fibril formation [299], and systemic administration of LPS in non-transgenic and transgenic $\mathrm{AD}$ mice induces neuroinflammation, $\mathrm{A} \beta$ deposition, and tau pathology [115, 128, 300, 301]. In addition, the presence of bacterial LPS has been reported in brain lysates from the hippocampus and superior temporal lobe neocortex of $\mathrm{AD}$ brains [302]. In a similar study, the levels of LPS and gram-negative $E$. coli fragments were greater in the post-mortem brain parenchyma and blood vessels of patients with AD compared with controls, and colocalized with amyloid plaques [301]. These studies provide evidence that implicates gut microbiomederived LPS as an important internal contributor to inflammatory degeneration in the CNS.

Recent studies have demonstrated that manipulating the gut microbiota can influence host innate immunity mechanisms which impact cerebral amyloid deposition and neuronal plasticity processes [294, 296, 303]. Promising preclinical data suggest that restoring homeostasis in the host-microbiota interactions in the elderly could be a way to improve intestinal inflammation and function, and influence their systemic inflammatory status. Prebiotics (nutritional support for bacteria), probiotics (live bacteria), symbiotics (combination of probiotics and prebiotics), certain antibiotics, and pharmacological inhibitors or activators have been shown to modulate the microbiota and correct inflammatory conditions in the elderly, thereby providing a potential means to 
counteract the development or progression of neurodegenerative diseases [304]. Despite the potential to slow or reverse pathology by modifying the diversity of the gut microbiota, further research is needed to better understand its complex interaction with $\mathrm{AD}$ biology, which could be essential to take preventive measure such as early diagnosis.

\section{Lifestyle as an anti-inflammatory modifier of $A D$ risk}

Learning and memory improvements have been observed when lifestyle factors are changed (i.e., increased exercise and low-fat diet). Considering the vast and varied ways in which $\mathrm{AD}$ and inflammation appear to intersect, it is fitting that researchers have also investigated whether inflammation could be modified to reduce the risk of AD. In the APP/PS1 mouse model of $\mathrm{AD}$, changing from a high-fat diet to a low-fat diet led to a return to baseline levels of neuroinflammation and reduced the levels of insoluble $A \beta$ [305]. A study focused on improving the nutrient status of APP/PS1 mice found that an improved diet also led to better performance in the Morris water maze [306]. Moreover, physical exercise has also been shown to rescue behavioral deficits caused by inflammation. In rats with induced neuroinflammation, access to a treadmill or running wheel led to improved escape latency and distance traveled to find a submerged platform in the Morris water maze [307]. As the induction of LTP is inhibited during neuroinflammation, researchers determined that exercise improved behavioral deficits by rescuing LTP. Aged mice have increased baseline neuroinflammation, expressing IL-1 $\beta$ and IL-10 at a greater level in the hippocampus than adult mice [308]. This effect can be attenuated by access to a running wheel, decreasing hippocampal cytokine levels as well as reducing the depressive "sickness behavior" observed in aged mice [308]. The behavioral deficits caused by intracerebroventricular injection of $A \beta$ were also shown to be attenuated when Swiss-albino mice performed swimming training [309]. This exercise training also reduced the levels of the pro-inflammatory cytokines IL-6 and IL-4 in both the prefrontal cortex and hippocampus via a decrease in NF- $k B$ activity [309]. In the 3xTg-AD mouse model, 8-week voluntary running wheel exercise led to reduced neurodegeneration and apoptosis, as well as a reduction in the pro-inflammatory cytokines TNF- $\alpha$ and IL-6, compared to $3 \times \mathrm{Tg}-\mathrm{AD}$ mice which did not [310]. Similar results were observed in 3xTg-AD mice which were administered insulin sensitizing drugs [311]. Kang and colleagues also showed that exercise could significantly reduce $A \beta$ plaque load in PS2 transgenic mice, simultaneously reducing TNF- $\alpha$ levels and apoptosis [312]. Given that inflammation can trigger
$A \beta$ synthesis, and that $A \beta$ can trigger inflammation, it is difficult to determine how the effects of exercise occur, particularly as there is also evidence that exercise reduces $\mathrm{BACE} 1$ and other facilitators of the $\mathrm{A} \beta$ production pathway [313]. However, recent research from $\mathrm{Lu}$ and colleagues using a rat model of $\mathrm{AD}$ showed that the positive effects of exercise were due to a microglial shift from the pro- to the anti-inflammatory phenotype, thereby reducing neuronal death [314]. This suggests that there is a direct, positive effect of exercise on the response of microglia, which may be able to reduce their aberrant effects during AD.

The effects of exercise have seldom been investigated with respect to tau pathology, although the available data appear promising. Providing THY-Tau 22 mice with access to a running wheel for 9 months resulted in reduced tau phosphorylation and a significant decrease in TNF- $\alpha$ and IL-1 $\beta$ [315]. However, short-term exercise was shown to increase microglial reactivity and the release of pro-inflammatory cytokines in both non-transgenic and $\operatorname{Tg} 601$ mice, together with an increase in phosphorylated tau in the transgenic mice [316]. This may be due to the shorter length of the exercise period, such that the positive effects observed with running, including brain-derived neurotrophic factor release, have not yet occurred. Our understanding of the effects of exercise on tau is still to reach consensus with respect to the involvement of inflammation; however, these data point towards a dose-dependent effect of exercise in animal models.

The effects of exercise and improved diet on cognition are clear, and these lifestyle changes have been tested on human patients with promising results. A meta-analysis of research in humans has shown that there is a distinct positive correlation with weight loss and improvement of cognitive functions [317]. Strength training in older women was found to improve their cognitive ability, while preventing the increase in TNF- $\alpha$ seen without such training [318]. In addition, high levels of pro-inflammatory IL-12p40 were found to correlate with rapid cognitive decline, an effect which was attenuated by exercise [319]. This suggests that exercise can modify neuroinflammation in a way that translates to improved cognition. However, further research into standardizing the optimal type and amount of exercise would be beneficial for the field.

\section{Conclusions}

Although the inflammatory response to acute incidents is tightly regulated, chronic inflammation is ineffective and can lead to worsened outcomes during many diseases. This is true in the case of AD, where inflammation becomes detrimental to neuronal survival and accelerates cognitive decline. The fact that the risks for 
AD involve various changes to homeostatic inflammatory responses is evidence of the clear clinical influence of inflammation on disease progression. A multitude of inflammatory events can occur throughout an individual's lifetime, and microglial priming observed during aging suggests that the baseline level of inflammation can shift over time. This may lead to a cumulative $\mathrm{AD}$ risk caused by a lifetime of inflammatory conditions, some of which involve genetic and lifestyle factors (Fig. 4).

Inflammation influences each of the hallmarks of $\mathrm{AD}$ (i.e., $A \beta$, tau and synaptic and neuronal loss), and to complicate this further, exerts different effects at different stages of AD progression (Fig. 5). For example, attenuating pro-inflammatory phagocytosis during the initial stages of A $\beta$ plaque accumulation has detrimental effects, but if pro-inflammatory signaling becomes chronic, it causes tau pathology to worsen and increases synaptic loss. Chronic inflammation therefore presents an interesting dilemma: would it improve patient outcomes to be able to reactivate microglia, enabling them to continue to clear $A \beta$ plaques and extending pro-inflammatory signaling, or would resolution of inflammation lead to better patient outcomes? Stimulation of phagocytosis without excessive pro-inflammatory signaling would be ideal in the treatment of $\mathrm{AD}$. Clearly, the timing of pro- and anti-inflammatory effects is key to both the pathology of $\mathrm{AD}$ and potentially its treatment.

Extensive research is therefore needed to find a way in which to provide the balance between pro- and anti-inflammatory responses to resolve the inflammation with appropriate timing, thereby avoiding the risk factors associated with chronic inflammation. However, in order to achieve this, tools such as immuno-based biomarkers

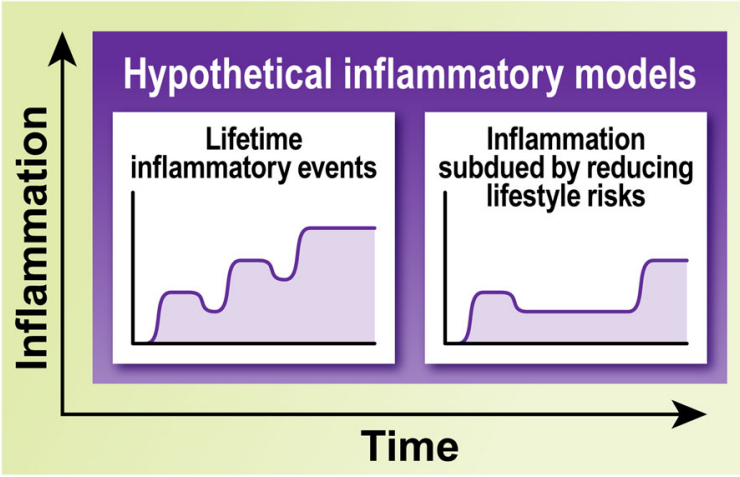

Fig. 4 Proposed model of immunosenescence over time. We suggest that immunosenescence is related to the cumulative effects of many inflammatory events throughout life, including infection, metabolic disorders, or genetic risks. It may be possible to reduce immunosenescence by modifying lifestyle, leading to a reduced cumulative effect, which may subsequently decrease the risk of developing $A D$

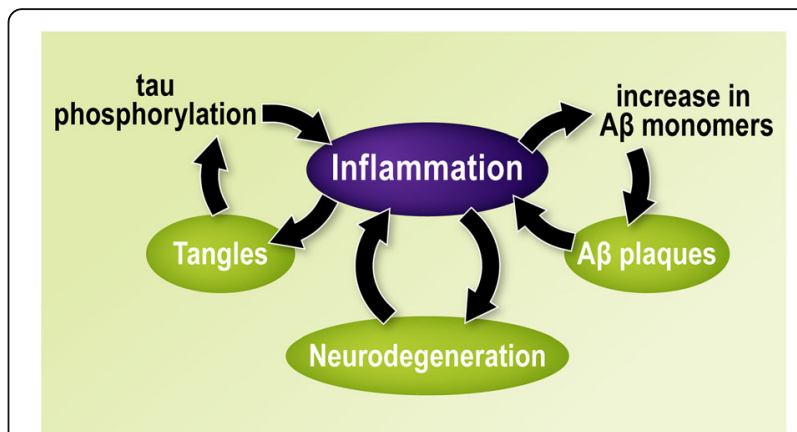

Fig. 5 Inflammation uniquely affects each of the hallmarks of AD. Each hallmark of AD has a unique relationship with inflammation, whereby it can both be triggered by and trigger inflammation. $A \beta$ plaques activate microglia and trigger their pro-inflammatory signaling pathways, which can cause increased $A \beta$ production. Tau phosphorylation can be caused by the production of $A \beta$ plaques, as well as by increased inflammatory signaling. Tau hyperphosphorylation and tangles can also lead to increased inflammation. Finally, neurodegeneration can be caused by an excessive microglial response, while neuronal debris from neurodegeneration can lead to further stimulation of microglia

need to be developed to allow the early detection of inflammatory diseases, so as to be able to modulate the inflammatory response and delay the onset and/or the progression of the disease. While scientists focus their efforts on achieving this aim, it is also important to highlight the relevance of actively promoting good habits, such as regular exercise, eating a healthy diet and avoiding harmful lifestyle risks, to minimize inflammation and its contribution to $\mathrm{AD}$ risk.

\section{Abbreviations}

ABC: ATP-binding cassette; AD: Alzheimer's disease; ADAM: A disintegrin and metalloproteinase; AMPAR: A-Amino-3hydorxy-5-methyl-4-isoxazolepropionic acid receptor; AP-1: Activator protein 1; ApoE: Apolipoprotein E; APP: Amyloid precursor protein; AB: $\beta$-Amyloid; BACE1: Beta-secretase-1; BBB: Blood-brain barrier; C1q: Complement component 1q; CCL: CC-chemokine ligand; CD: Cluster of differentiation; CDK5: Cyclin-dependent kinase 5; CKLF1: Chemokinelike factor 1; CNS: Central nervous system; COX-2: Cyclooxygenase-2; CX3CR1: CX3C chemokine receptor 1; CXCL: CXC-chemokine ligand; DAMP: Danger-associated molecular pattern; EP4: Prostaglandin E2 receptor 4; ERK: Extracellular signal-regulated kinase; FAD: Familial AD; GSK3 $\beta$ : Glycogen synthase kinase-3 $\beta$; GULP1: Engulfment adapter PTB domain containing 1; GWAS: Genome-wide association studies; Iba1: Ionized calcium binding adaptor molecule 1; IDE: Insulin degrading enzyme; IFNү: Interferon- $\gamma ;$ IL: Interleukin; iNOS: Inducible nitric oxide synthase; JNK: C-Jun N-terminal kinase; LOX: Lipoxygenase; LPS: Lipopolysaccharide; LRP1: Lipoprotein receptor-related protein-1; LTP: Long-term potentiation; $\mathrm{LXA}_{4}$ : Lipoxin A4; MEGF10: Multiple epidermal growth factor-like domains 10; MerTK: C-MER proto-oncogene tyrosine kinase; MHC-II: Major histocompatibility complex-II; MLA: Monophosphoryl lipid A; MMP: Matrix metalloproteinase; NALP3: NACHT, LRR and PYD domains-containing protein 3; NFTs: Neurofibrillary tangles; NF-KB: Nuclear factor-KB; NLRP3: Nlr family pyrin domain containing 3; NMDAR: N-methyl-D-aspartate receptor; p38-MAPK: p38 mitogen-activated protein kinase; PGE $_{2}$ : Prostaglandin $\mathrm{E}_{2}$; PHF-1: PHD finger protein-1; PPAR-Y: Peroxisome proliferator-activated receptor-ү; RAGE: Receptor for advanced glycation end products; RvE1: Resolvin E1; SNPs: Single nucleotide polymorphisms; SRA: Scavenger receptor A; STAT3: Signal transducer and activator of transcription 3; STREM: Soluble TREM2; T2DM: Type 2 diabetes mellitus; TBI: Traumatic brain injury; TGF- $\beta$ : Transforming growth factor- $\beta$; 
TLR: Toll-like receptor; TNFR1: TNF-type 1 death receptor; TNF-a: Tumor necrosis factor-a; TREM2: Triggering Receptor Expressed on Myeloid Cells 2; TYROBP: TYRO protein tyrosine kinase binding protein

\section{Acknowledgements}

We appreciate the editing support from Ms. Rowan Tweedale.

\section{Funding}

This work was funded by the Australian National Health and Medical Research Council (GNT1128436, GNT1129192, GNT1139469).

\section{Authors' contributions}

This work was primarily written by EN and RM, with contributions from JCP, MLS, and TJH. Figures were produced by NV. All authors read and approved the final manuscript.

\section{Ethics approval and consent to participate} Not applicable.

\section{Consent for publication}

Not applicable.

\section{Competing interests}

The authors declare that they have no competing interests.

\section{Publisher's Note}

Springer Nature remains neutral with regard to jurisdictional claims in published maps and institutional affiliations.

\section{Author details}

'Neurula Laboratory, Clem Jones Centre for Ageing Dementia Research, Queensland Brain Institute, The University of Queensland, Building 79, Brisbane 4072, QLD, Australia. ${ }^{2}$ Queensland Brain Institute, The University of Queensland, Brisbane 4072, QLD, Australia. ${ }^{3}$ Centre for Stem Cell Ageing and Regenerative Engineering, The University of Queensland, Brisbane 4072, QLD, Australia.

Received: 31 July 2018 Accepted: 11 September 2018 Published online: 24 September 2018

\section{References}

1. Cummings J, Lee G, Mortsdorf T, Ritter A, Zhong K. Alzheimer's disease drug development pipeline: 2017. Alzheimers Dement (N Y). 2017;3(3):367-84

2. Fullerton JN, Gilroy DW. Resolution of inflammation: a new therapeutic frontier. Nat Rev Drug Discov. 2016;15(8):551-67.

3. Tay TL, Mai D, Dautzenberg J, Fernandez-Klett F, Lin G, Sagar, et al. A new fate mapping system reveals context-dependent random or clonal expansion of microglia. Nat Neurosci. 2017:20(6):793-803.

4. Grabert K, Michoel T, Karavolos MH, Clohisey S, Baillie JK, Stevens MP, et al. Microglial brain region-dependent diversity and selective regional sensitivities to aging. Nat Neurosci. 2016;19(3):504-16.

5. Askew K, Li K, Olmos-Alonso A, Garcia-Moreno F, Liang Y, Richardson P, et al. Coupled proliferation and apoptosis maintain the rapid turnover of microglia in the adult brain. Cell Rep. 2017;18(2):391-405.

6. Zamanian JL, Xu L, Foo LC, Nouri N, Zhou L, Giffard RG, et al. Genomic analysis of reactive astrogliosis. J Neurosci. 2012;32(18):6391-410.

7. Livne-Bar I, Wei J, Liu HH, Alqawlaq S, Won GJ, Tuccitto A, et al. Astrocytederived lipoxins $\mathrm{A} 4$ and $\mathrm{B} 4$ promote neuroprotection from acute and chronic injury. J Clin Invest. 2017:127(12):4403-14.

8. Vainchtein ID, Chin G, Cho FS, Kelley KW, Miller JG, Chien EC, et al. Astrocyte-derived interleukin-33 promotes microglial synapse engulfment and neural circuit development. Science. 2018;359(6381):1269-73.

9. Habbas S, Santello M, Becker D, Stubbe H, Zappia G, Liaudet N, et al. Neuroinflammatory TNFalpha impairs memory via astrocyte signaling. Cell. 2015;163(7):1730-41.

10. Anderson MA, Burda JE, Ren Y, Ao Y, O'Shea TM, Kawaguchi R, et al. Astrocyte scar formation aids central nervous system axon regeneration. Nature. 2016:532(7598):195-200.

11. Liddelow SA, Guttenplan KA, Clarke LE, Bennett FC, Bohlen CJ, Schirmer L, et al. Neurotoxic reactive astrocytes are induced by activated microglia. Nature. 2017;541(7638):481-7.
12. Cribbs DH, Berchtold NC, Perreau V, Coleman PD, Rogers J, Tenner AJ, et al. Extensive innate immune gene activation accompanies brain aging, increasing vulnerability to cognitive decline and neurodegeneration: a microarray study. J Neuroinflammation. 2012:9:179.

13. Galatro TF, Holtman IR, Lerario AM, Vainchtein ID, Brouwer N, Sola PR, et al. Transcriptomic analysis of purified human cortical microglia reveals ageassociated changes. Nat Neurosci. 2017;20(8):1162-71.

14. Streit WJ, Sammons NW, Kuhns AJ, Sparks DL. Dystrophic microglia in the aging human brain. Glia. 2004;45(2):208-12.

15. Mrdjen D, Pavlovic A, Hartmann FJ, Schreiner B, Utz SG, Leung BP, et al. High-dimensional single-cell mapping of central nervous system immune cells reveals distinct myeloid subsets in health, aging, and disease. Immunity. 2018;48(2):380-95 e6.

16. Ritzel RM, Patel AR, Pan S, Crapser J, Hammond M, Jellison E, et al. Age- and location-related changes in microglial function. Neurobiol Aging. 2015;36(6): 2153-63.

17. Vukovic J, Colditz MJ, Blackmore DG, Ruitenberg MJ, Bartlett PF. Microglia modulate hippocampal neural precursor activity in response to exercise and aging. J Neurosci. 2012;32(19):6435-43.

18. Wendeln AC, Degenhardt K, Kaurani L, Gertig M, Ulas T, Jain G, et al. Innate immune memory in the brain shapes neurological disease hallmarks. Nature. 2018;556(7701):332-8.

19. Njie EG, Boelen E, Stassen FR, Steinbusch HW, Borchelt DR, Streit WJ. Ex vivo cultures of microglia from young and aged rodent brain reveal age-related changes in microglial function. Neurobiol Aging. 2012;33(1):195 e1-12.

20. Bliederhaeuser C, Grozdanov V, Speidel A, Zondler L, Ruf WP, Bayer H, et al. Age-dependent defects of alpha-synuclein oligomer uptake in microglia and monocytes. Acta Neuropathol. 2016;131(3):379-91.

21. Rawji KS, Kappen J, Tang W, Teo W, Plemel JR, Stys PK, et al. Deficient surveillance and phagocytic activity of myeloid cells within demyelinated lesions in aging mice visualized by ex vivo live multiphoton imaging. J Neurosci. 2018;38(8):1973-88.

22. Safaiyan S, Kannaiyan N, Snaidero N, Brioschi S, Biber K, Yona S, et al. Agerelated myelin degradation burdens the clearance function of microglia during aging. Nat Neurosci. 2016;19(8):995-8.

23. Montagne A, Barnes SR, Sweeney MD, Halliday MR, Sagare AP, Zhao Z, et al. Blood-brain barrier breakdown in the aging human hippocampus. Neuron. 2015:85(2):296-302.

24. Walker KA, Hoogeveen RC, Folsom AR, Ballantyne CM, Knopman DS, Windham $B G$, et al. Midlife systemic inflammatory markers are associated with late-life brain volume: the ARIC study. Neurology. 2017;89(22):2262-70.

25. Takechi R, Lam V, Brook E, Giles C, Fimognari N, Mooranian A, et al. Blood-brain barrier dysfunction precedes cognitive decline and neurodegeneration in diabetic insulin resistant mouse model: an implication for causal link. Front Aging Neurosci. 2017;9:399.

26. Villeda SA, Luo J, Mosher KI, Zou B, Britschgi M, Bieri G, et al. The ageing systemic milieu negatively regulates neurogenesis and cognitive function. Nature. 2011:477(7362):90-4.

27. Horng S, Therattil A, Moyon S, Gordon A, Kim K, Argaw AT, et al. Astrocytic tight junctions control inflammatory CNS lesion pathogenesis. J Clin Invest. 2017:127(8):3136-51.

28. Elahy M, Jackaman C, Mamo JC, Lam V, Dhaliwal SS, Giles C, et al. Bloodbrain barrier dysfunction developed during normal aging is associated with inflammation and loss of tight junctions but not with leukocyte recruitment. Immun Ageing. 2015:12:2.

29. Bell RD, Winkler EA, Sagare AP, Singh I, LaRue B, Deane R, et al. Pericytes control key neurovascular functions and neuronal phenotype in the adult brain and during brain aging. Neuron. 2010;68(3):409-27.

30. Orre M, Kamphuis W, Osborn LM, Melief J, Kooijman L, Huitinga I, et al, Acute isolation and transcriptome characterization of cortical astrocytes and microglia from young and aged mice. Neurobiol Aging. 2014;35(1): $1-14$

31. Clarke LE, Liddelow SA, Chakraborty C, Munch AE, Heiman M, Barres BA. Normal aging induces A1-like astrocyte reactivity. Proc Natl Acad Sci U S A. 2018;115(8):E1896-E905.

32. Wang $Y$, Jin $S$, Sonobe $Y$, Cheng $Y$, Horiuchi $H$, Parajuli B, et al. Interleukin1 beta induces blood-brain barrier disruption by downregulating Sonic hedgehog in astrocytes. PLoS One. 2014;9(10):e110024.

33. Alvarez JI, Dodelet-Devillers A, Kebir H, Ifergan I, Fabre PJ, Terouz S, et al. The hedgehog pathway promotes blood-brain barrier integrity and CNS immune quiescence. Science. 2011;334(6063):1727-31. 
34. Arai Y, Martin-Ruiz CM, Takayama M, Abe Y, Takebayashi T, Koyasu S, et al. Inflammation, but not telomere length, predicts successful ageing at extreme old age: a longitudinal study of semi-supercentenarians. EBioMedicine. 2015;2(10):1549-58.

35. Liddelow SA, Barres BA. Reactive astrocytes: production, function, and therapeutic potential. Immunity. 2017;46(6):957-67.

36. Fuger $P$, Hefendehl JK, Veeraraghavalu K, Wendeln AC, Schlosser C, Obermuller $U$, et al. Microglia turnover with aging and in an Alzheimer's model via long-term in vivo single-cell imaging. Nat Neurosci. 2017;20(10):1371-6.

37. Rice RA, Pham J, Lee RJ, Najafi AR, West BL, Green KN. Microglial repopulation resolves inflammation and promotes brain recovery after injury. Glia. 2017;65(6):931-44.

38. Puzzo D, Privitera L, Leznik E, Fa M, Staniszewski A, Palmeri A, et al. Picomolar amyloid-beta positively modulates synaptic plasticity and memory in hippocampus. J Neurosci. 2008;28(53):14537-45.

39. Liu S, Liu Y, Hao W, Wolf L, Kiliaan AJ, Penke B, et al. TLR2 is a primary receptor for Alzheimer's amyloid beta peptide to trigger neuroinflammatory activation. J Immunol. 2012;188(3):1098-107.

40. Deane R, Du Yan S, Submamaryan RK, LaRue B, Jovanovic S, Hogg E, et al. RAGE mediates amyloid-beta peptide transport across the blood-brain barrier and accumulation in brain. Nat Med. 2003;9(7):907-13.

41. Yan SD, Chen X, Fu J, Chen M, Zhu H, Roher A, et al. RAGE and amyloidbeta peptide neurotoxicity in Alzheimer's disease. Nature. 1996;382(6593): 685-91.

42. Medeiros R, Prediger RD, Passos GF, Pandolfo P, Duarte FS, Franco JL, et al. Connecting TNF-alpha signaling pathways to iNOS expression in a mouse model of Alzheimer's disease: relevance for the behavioral and synaptic deficits induced by amyloid beta protein. J Neurosci. 2007;27(20):5394-404

43. Bonaiuto C, McDonald PP, Rossi F, Cassatella MA. Activation of nuclear factor-kappa B by beta-amyloid peptides and interferon-gamma in murine microglia. J Neuroimmunol. 1997;77(1):51-6.

44. Medeiros R, Figueiredo CP, Pandolfo P, Duarte FS, Prediger RD, Passos GF, et al. The role of TNF-alpha signaling pathway on COX-2 upregulation and cognitive decline induced by beta-amyloid peptide. Behav Brain Res. 2010; 209(1):165-73.

45. Soscia SJ, Kirby JE, Washicosky KJ, Tucker SM, Ingelsson M, Hyman B, et al. The Alzheimer's disease-associated amyloid beta-protein is an antimicrobial peptide. PLoS One. 2010;5(3):e9505.

46. Grilli M, Ribola M, Alberici A, Valerio A, Memo M, Spano P. Identification and characterization of a kappa $\mathrm{B} /$ Rel binding site in the regulatory region of the amyloid precursor protein gene. J Biol Chem. 1995;270(45):26774-7.

47. Bourne KZ, Ferrari DC, Lange-Dohna C, Rossner S, Wood TG, Perez-Polo JR. Differential regulation of BACE1 promoter activity by nuclear factor-kappaB in neurons and glia upon exposure to beta-amyloid peptides. J Neurosci Res. 2007;85(6):1194-204

48. Cho HJ, Kim SK, Jin SM, Hwang EM, Kim YS, Huh K, et al. IFN-gammainduced BACE1 expression is mediated by activation of JAK2 and ERK1/2 signaling pathways and direct binding of STAT1 to BACE1 promoter in astrocytes. Glia. 2007;55(3):253-62

49. Sastre M, Dewachter I, Rossner S, Bogdanovic N, Rosen E, Borghgraef $P$, et al. Nonsteroidal anti-inflammatory drugs repress beta-secretase gene promoter activity by the activation of PPARgamma. Proc Natl Acad Sci U S A. 2006;103(2):443-8.

50. Chami L, Buggia-Prevot V, Duplan E, Del Prete D, Chami M, Peyron JF, et al. Nuclear factor-kappaB regulates betaAPP and beta- and gamma-secretases differently at physiological and supraphysiological Abeta concentrations. J Biol Chem. 2012;287(29):24573-84.

51. Hong HS, Hwang EM, Sim HJ, Cho HJ, Boo JH, Oh SS, et al. Interferon gamma stimulates beta-secretase expression and sAPPbeta production in astrocytes. Biochem Biophys Res Commun. 2003;307(4):922-7.

52. He P, Zhong Z, Lindholm K, Berning L, Lee W, Lemere C, et al. Deletion of tumor necrosis factor death receptor inhibits amyloid beta generation and prevents learning and memory deficits in Alzheimer's mice. J Cell Biol. 2007; 178(5):829-41

53. Yang H, Zhuo JM, Chu J, Chinnici C, Pratico D. Amelioration of the Alzheimer's disease phenotype by absence of 12/15-lipoxygenase. Biol Psychiatry. 2010;68(10):922-9.

54. Varga T, Czimmerer Z, Nagy L. PPARs are a unique set of fatty acid regulated transcription factors controlling both lipid metabolism and inflammation. Biochim Biophys Acta. 2011;1812(8):1007-22.
55. Katsouri L, Lim YM, Blondrath K, Eleftheriadou I, Lombardero L, Birch AM, et al. PPARgamma-coactivator-1alpha gene transfer reduces neuronal loss and amyloid-beta generation by reducing betasecretase in an Alzheimer's disease model. Proc Natl Acad Sci U S A. 2016;113(43):12292-7

56. Chu J, Pratico D. The 5-lipoxygenase as modulator of Alzheimer's gammasecretase and therapeutic target. Brain Res Bull. 2016;126(Pt 2):207-12.

57. Lu B, Figini M, Emanueli C, Geppetti P, Grady EF, Gerard NP, et al. The control of microvascular permeability and blood pressure by neutral endopeptidase. Nat Med. 1997;3(8):904-7.

58. Sturiale S, Barbara G, Qiu B, Figini M, Geppetti P, Gerard N, et al. Neutral endopeptidase (EC 3.4.24.11) terminates colitis by degrading substance $P$. Proc Natl Acad Sci U S A. 1999;96(20):11653-8.

59. Kirkwood KS, Bunnett NW, Maa J, Castagliolo I, Liu B, Gerard N, et al. Deletion of neutral endopeptidase exacerbates intestinal inflammation induced by Clostridium difficile toxin A. Am J Physiol Gastrointest Liver Physiol. 2001;281(2):G544-51.

60. Scholzen TE, Steinhoff M, Bonaccorsi P, Klein R, Amadesi S, Geppetti P, et al. Neutral endopeptidase terminates substance P-induced inflammation in allergic contact dermatitis. J Immunol. 2001;166(2):1285-91.

61. Kong Y, Ruan L, Qian L, Liu X, Le Y. Norepinephrine promotes microglia to uptake and degrade amyloid beta peptide through upregulation of mouse formyl peptide receptor 2 and induction of insulin-degrading enzyme. J Neurosci. 2010;30(35):11848-57.

62. Liu CC, Hu J, Zhao N, Wang J, Wang N, Cirrito JR, et al. Astrocytic LRP1 mediates brain Abeta clearance and impacts amyloid deposition. J Neurosci. 2017:37(15):4023-31.

63. Ren M, Guo Q, Guo L, Lenz M, Qian F, Koenen RR, et al. Polymerization of MIP-1 chemokine (CCL3 and CCL4) and clearance of MIP-1 by insulindegrading enzyme. EMBO J. 2010;29(23):3952-66.

64. Hellstrom-Lindahl E, Ravid R, Nordberg A. Age-dependent decline of neprilysin in Alzheimer's disease and normal brain: inverse correlation with A beta levels. Neurobiol Aging. 2008;29(2):210-21.

65. Zhao Z, Xiang Z, Haroutunian V, Buxbaum JD, Stetka B, Pasinetti GM. Insulin degrading enzyme activity selectively decreases in the hippocampal formation of cases at high risk to develop Alzheimer's disease. Neurobiol Aging. 2007;28(6):824-30.

66. Spampinato SF, Merlo S, Sano Y, Kanda T, Sortino MA. Astrocytes contribute to Abeta-induced blood-brain barrier damage through activation of endothelial MMP9. J Neurochem. 2017;142(3):464-77.

67. Kanekiyo T, Cirrito JR, Liu CC, Shinohara M, Li J, Schuler DR, et al. Neuronal clearance of amyloid-beta by endocytic receptor LRP1. J Neurosci. 2013; 33(49):19276-83.

68. Storck SE, Meister S, Nahrath J, Meissner JN, Schubert N, Di Spiezio A, et al. Endothelial LRP1 transports amyloid-beta(1-42) across the blood-brain barrier. J Clin Invest. 2016;126(1):123-36.

69. Fernandez-Castaneda A, Arandjelovic S, Stiles TL, Schlobach RK, Mowen KA, Gonias SL, et al. Identification of the low density lipoprotein (LDL) receptor-related protein-1 interactome in central nervous system myelin suggests a role in the clearance of necrotic cell debris. J Biol Chem. 2013;288(7):4538-48.

70. Chuang TY, Guo Y, Seki SM, Rosen AM, Johanson DM, Mandell JW, et al. LRP1 expression in microglia is protective during CNS autoimmunity. Acta Neuropathol Commun. 2016;4(1):68.

71. Mantuano E, Brifault C, Lam MS, Azmoon P, Gilder AS, Gonias SL. LDL receptor-related protein-1 regulates NFkappaB and microRNA-155 in macrophages to control the inflammatory response. Proc Natl Acad Sci U S A. 2016;113(5):1369-74.

72. Yang L, Liu CC, Zheng H, Kanekiyo T, Atagi Y, Jia L, et al. LRP1 modulates the microglial immune response via regulation of JNK and NF-kappaB signaling pathways. J Neuroinflammation. 2016;13(1):304.

73. Kang DE, Pietrzik CU, Baum L, Chevallier N, Merriam DE, Kounnas MZ, et al. Modulation of amyloid beta-protein clearance and Alzheimer's disease susceptibility by the LDL receptor-related protein pathway. J Clin Invest. 2000;106(9):1159-66.

74. Osgood D, Miller MC, Messier AA, Gonzalez L, Silverberg GD. Aging alters mRNA expression of amyloid transporter genes at the blood-brain barrier. Neurobiol Aging. 2017:57:178-85.

75. Steinberg S, Stefansson H, Jonsson T, Johannsdottir H, Ingason A, Helgason $\mathrm{H}$, et al. Loss-of-function variants in ABCA7 confer risk of Alzheimer's disease. Nat Genet. 2015;47(5):445-7. 
76. De Roeck A, Van den Bossche T, van der Zee J, Verheijen J, De Coster W Van Dongen J, et al. Deleterious ABCA7 mutations and transcript rescue mechanisms in early onset Alzheimer's disease. Acta Neuropathol. 2017; 134(3):475-87.

77. Karasinska JM, de Haan W, Franciosi S, Ruddle P, Fan J, Kruit JK, et al. ABCA1 influences neuroinflammation and neuronal death. Neurobiol Dis. 2013;54: 445-55

78. Jehle AW, Gardai SJ, Li S, Linsel-Nitschke P, Morimoto K, Janssen WJ, et al. ATP-binding cassette transporter A7 enhances phagocytosis of apoptotic cells and associated ERK signaling in macrophages. J Cell Biol. 2006;174(4): 547-56.

79. Morizawa YM, Hirayama Y, Ohno N, Shibata S, Shigetomi E, Sui Y, et al. Reactive astrocytes function as phagocytes after brain ischemia via ABCA1mediated pathway. Nat Commun. 2017:8(1):28

80. Fu Y, Hsiao JH, Paxinos G, Halliday GM, Kim WS. ABCA7 mediates phagocytic clearance of amyloid-beta in the brain. J Alzheimers Dis. 2016;54(2):569-84.

81. Kim WS, Bhatia S, Elliott DA, Agholme L, Kagedal K, McCann H, et al. Increased ATP-binding cassette transporter A1 expression in Alzheimer's disease hippocampal neurons. J Alzheimers Dis. 2010;21(1):193-205.

82. Vasquez JB, Fardo DW, Estus S. ABCA7 expression is associated with Alzheimer's disease polymorphism and disease status. Neurosci Lett. 2013; 556:58-62.

83. Hickman SE, Allison EK, El Khoury J. Microglial dysfunction and defective beta-amyloid clearance pathways in aging Alzheimer's disease mice. J Neurosci. 2008;28(33):8354-60.

84. Castillo E, Leon J, Mazzei G, Abolhassani N, Haruyama N, Saito T, et al. Comparative profiling of cortical gene expression in Alzheimer's disease patients and mouse models demonstrates a link between amyloidosis and neuroinflammation. Sci Rep. 2017;7(1):17762.

85. Thakker DR, Sankaranarayanan S, Weatherspoon MR, Harrison J, Pierdomenico M, Heisel JM, et al. Centrally delivered BACE1 inhibitor activates microglia, and reverses amyloid pathology and cognitive deficit in aged Tg2576 mice. J Neurosci. 2015;35(17):6931-6.

86. Streit WJ, Braak H, Xue QS, Bechmann I. Dystrophic (senescent) rather than activated microglial cells are associated with tau pathology and likely precede neurodegeneration in Alzheimer's disease. Acta Neuropathol. 2009; 118(4):475-85

87. Brawek B, Schwendele B, Riester K, Kohsaka S, Lerdkrai C, Liang Y, et al. Impairment of in vivo calcium signaling in amyloid plaque-associated microglia. Acta Neuropathol. 2014;127(4):495-505.

88. Lucin KM, O'Brien CE, Bieri G, Czirr E, Mosher Kl, Abbey RJ, et al. Microglial beclin 1 regulates retromer trafficking and phagocytosis and is impaired in Alzheimer's disease. Neuron. 2013;79(5):873-86

89. Fan Z, Brooks DJ, Okello A, Edison P. An early and late peak in microglial activation in Alzheimer's disease trajectory. Brain. 2017;140(3): 792-803.

90. Keren-Shaul H, Spinrad A, Weiner A, Matcovitch-Natan O, Dvir-Szternfeld R, Ulland TK, et al. A unique microglia type associated with restricting development of Alzheimer's disease. Cell. 2017;169(7):1276-90 e17.

91. Seabrook TJ, Jiang L, Maier M, Lemere CA. Minocycline affects microglia activation, Abeta deposition, and behavior in APP-tg mice. Glia. 2006;53(7): 776-82

92. Grathwohl SA, Kalin RE, Bolmont T, Prokop S, Winkelmann G, Kaeser SA, et al. Formation and maintenance of Alzheimer's disease betaamyloid plaques in the absence of microglia. Nat Neurosci. 2009; 12(11):1361-3.

93. Olmos-Alonso A, Schetters ST, Sri S, Askew K, Mancuso R, Vargas-Caballero $M$, et al. Pharmacological targeting of CSF1R inhibits microglial proliferation and prevents the progression of Alzheimer's-like pathology. Brain. 2016; 139(Pt 3):891-907.

94. Dagher NN, Najafi AR, Kayala KM, Elmore MR, White TE, Medeiros R, et al. Colony-stimulating factor 1 receptor inhibition prevents microglial plaque association and improves cognition in 3xTg-AD mice. J Neuroinflammation. 2015;12:139

95. Spangenberg EE, Lee RJ, Najafi AR, Rice RA, Elmore MR, Blurton-Jones M, et al. Eliminating microglia in Alzheimer's mice prevents neuronal loss without modulating amyloid-beta pathology. Brain. 2016;139(Pt 4):1265-81.

96. Lee $\mathrm{S}$, Varvel NH, Konerth ME, Xu G, Cardona AE, Ransohoff RM, et al. CX3CR1 deficiency alters microglial activation and reduces beta-amyloid deposition in two Alzheimer's disease mouse models. Am J Pathol. 2010; 177(5):2549-62.
97. Fuhrmann M, Bittner T, Jung CK, Burgold S, Page RM, Mitteregger G, et al. Microglial $\mathrm{Cx} 3 \mathrm{Cr} 1$ knockout prevents neuron loss in a mouse model of Alzheimer's disease. Nat Neurosci. 2010;13(4):411-3.

98. Heneka MT, Kummer MP, Stutz A, Delekate A, Schwartz S, Vieira-Saecker A, et al. NLRP3 is activated in Alzheimer's disease and contributes to pathology in APP/PS1 mice. Nature. 2013;493(7434):674-8.

99. Fu AK, Hung KW, Yuen MY, Zhou X, Mak DS, Chan IC, et al. IL-33 ameliorates Alzheimer's disease-like pathology and cognitive decline. Proc Natl Acad Sci U S A. 2016;113(19):E2705-13.

100. Fonseca MI, Zhou J, Botto M, Tenner AJ. Absence of C1q leads to less neuropathology in transgenic mouse models of Alzheimer's disease. $J$ Neurosci. 2004;24(29):6457-65.

101. Czirr E, Castello NA, Mosher Kl, Castellano JM, Hinkson IV, Lucin KM, et al. Microglial complement receptor 3 regulates brain Abeta levels through secreted proteolytic activity. J Exp Med. 2017:214(4):1081-92.

102. Shi Q, Chowdhury S, Ma R, Le KX, Hong S, Caldarone BJ, et al. Complement C3 deficiency protects against neurodegeneration in aged plaque-rich APP/ PS1 mice. Sci Transl Med. 2017;9(392):eaaf6295.

103. Hernandez MX, Jiang S, Cole TA, Chu SH, Fonseca MI, Fang MJ, et al, Prevention of C5aR1 signaling delays microglial inflammatory polarization, favors clearance pathways and suppresses cognitive loss. Mol Neurodegener. 2017;12(1):66.

104. Liu Y, Liu X, Hao W, Decker Y, Schomburg R, Fulop L, et al. IKKbeta deficiency in myeloid cells ameliorates Alzheimer's disease-related symptoms and pathology. J Neurosci. 2014;34(39):12982-99.

105. Michaud JP, Halle M, Lampron A, Theriault P, Prefontaine P, Filali M, et al. Toll-like receptor 4 stimulation with the detoxified ligand monophosphoryl lipid A improves Alzheimer's disease-related pathology. Proc Natl Acad Sci U S A. 2013;110(5):1941-6.

106. Cluff CW. Monophosphoryl lipid A (MPL) as an adjuvant for anti-cancer vaccines: clinical results. Adv Exp Med Biol. 2010;667:111-23.

107. Guillot-Sestier MV, Doty KR, Gate D, Rodriguez J Jr, Leung BP, Rezai-Zadeh K, et al. $\| 10$ deficiency rebalances innate immunity to mitigate Alzheimer-like pathology. Neuron. 2015;85(3):534-48.

108. Chakrabarty P, Li A, Ceballos-Diaz C, Eddy JA, Funk CC, Moore B, et al. IL-10 alters immunoproteostasis in APP mice, increasing plaque burden and worsening cognitive behavior. Neuron. 2015;85(3):519-33.

109. Medeiros R, Kitazawa M, Passos GF, Baglietto-Vargas D, Cheng D, Cribbs DH, et al. Aspirin-triggered lipoxin A4 stimulates alternative activation of microglia and reduces Alzheimer disease-like pathology in mice. Am J Pathol. 2013;182(5):1780-9.

110. Dunn HC, Ager RR, Baglietto-Vargas D, Cheng D, Kitazawa M, Cribbs DH, et al, Restoration of lipoxin A4 signaling reduces Alzheimer's disease-like pathology in the 3xTg-AD mouse model. J Alzheimers Dis. 2015;43(3):893-903.

111. Woodling NS, Wang Q, Priyam PG, Larkin P, Shi J, Johansson JU, et al. Suppression of Alzheimer-associated inflammation by microglial prostaglandinE2 EP4 receptor signaling. J Neurosci. 2014;34(17):5882-94.

112. Brosseron F, Krauthausen $M$, Kummer M, Heneka MT. Body fluid cytokine levels in mild cognitive impairment and Alzheimer's disease: a comparative overview. Mol Neurobiol. 2014;50(2):534-44.

113. Wang X, Zhu M, Hjorth E, Cortes-Toro V, Eyjolfsdottir H, Graff C, et al. Resolution of inflammation is altered in Alzheimer's disease. Alzheimers Dement. 2015;11(1):40-50 e1-2.

114. Marin I, Kipnis J. Learning and memory ... and the immune system. Learn Mem. 2013;20(10):601-6.

115. Kitazawa M, Oddo S, Yamasaki TR, Green KN, LaFerla FM. Lipopolysaccharide-induced inflammation exacerbates tau pathology by a cyclin-dependent kinase 5-mediated pathway in a transgenic model of Alzheimer's disease. J Neurosci. 2005;25(39):8843-53.

116. Kitazawa M, Trinh DN, LaFerla FM. Inflammation induces tau pathology in inclusion body myositis model via glycogen synthase kinase-3beta. Ann Neurol. 2008;64(1):15-24

117. Bhaskar K, Konerth M, Kokiko-Cochran ON, Cardona A, Ransohoff RM, Lamb BT. Regulation of tau pathology by the microglial fractalkine receptor. Neuron. 2010;68(1):19-31.

118. Maphis N, Xu G, Kokiko-Cochran ON, Jiang S, Cardona A, Ransohoff RM, et al. Reactive microglia drive tau pathology and contribute to the spreading of pathological tau in the brain. Brain. 2015;138(Pt 6): 1738-55.

119. Sanchez-Mejias E, Navarro V, Jimenez S, Sanchez-Mico M, Sanchez-Varo R, Nunez-Diaz C, et al. Soluble phospho-tau from Alzheimer's disease 
hippocampus drives microglial degeneration. Acta Neuropathol. 2016;132(6): 897-916.

120. Yoshiyama Y, Higuchi M, Zhang B, Huang SM, Iwata N, Saido TC, et al. Synapse loss and microglial activation precede tangles in a P301S tauopathy mouse model. Neuron. 2007;53(3):337-51.

121. Maphis N, Xu G, Kokiko-Cochran ON, Cardona AE, Ransohoff RM, Lamb BT, et al. Loss of tau rescues inflammation-mediated neurodegeneration. Front Neurosci. 2015;9:196.

122. Asai H, Ikezu S, Tsunoda S, Medalla M, Luebke J, Haydar T, et al. Depletion of microglia and inhibition of exosome synthesis halt tau propagation. Nat Neurosci. 2015;18(11):1584-93.

123. Gorlovoy P, Larionov S, Pham TT, Neumann H. Accumulation of tau induced in neurites by microglial proinflammatory mediators. FASEB J. 2009;23(8): 2502-13.

124. Noble W, Garwood C, Stephenson J, Kinsey AM, Hanger DP, Anderton BH. Minocycline reduces the development of abnormal tau species in models of Alzheimer's disease. FASEB J. 2009;23(3):739-50.

125. Hunt JB Jr, Nash KR, Placides D, Moran P, Selenica ML, Abuqalbeen F, et al. Sustained arginase 1 expression modulates pathological tau deposits in a mouse model of tauopathy. J Neurosci. 2015;35(44):14842-60.

126. Roe AD, Staup MA, Serrats J, Sawchenko PE, Rissman RA. Lipopolysaccharide-induced tau phosphorylation and kinase activity-modulation, but not mediation, by corticotropin-releasing factor receptors. Eur J Neurosci. 2011;34(3):448-56.

127. Lee DC, Rizer J, Selenica ML, Reid P, Kraft C, Johnson A, et al. LPS- induced inflammation exacerbates phospho-tau pathology in rTg4510 mice. J Neuroinflammation. 2010;7:56.

128. Sy M, Kitazawa M, Medeiros $R$, Whitman $L$, Cheng $D$, Lane TE, et al. Inflammation induced by infection potentiates tau pathological features in transgenic mice. Am J Pathol. 2011;178(6):2811-22.

129. Piras A, Collin L, Gruninger F, Graff C, Ronnback A. Autophagic and lysosomal defects in human tauopathies: analysis of post-mortem brain from patients with familial Alzheimer disease, corticobasal degeneration and progressive supranuclear palsy. Acta Neuropathol Commun. 2016:4:22.

130. Kitazawa M, Cheng D, Tsukamoto MR, Koike MA, Wes PD, Vasilevko V, et al. Blocking IL-1 signaling rescues cognition, attenuates tau pathology, and restores neuronal beta-catenin pathway function in an Alzheimer's disease model. J Immunol. 2011;187(12):6539-49.

131. Cho SH, Chen JA, Sayed F, Ward ME, Gao F, Nguyen TA, et al. SIRT1 deficiency in microglia contributes to cognitive decline in aging and neurodegeneration via epigenetic regulation of IL-1 beta. J Neurosci. 2015; 35(2):807-18.

132. Ghosh S, Wu MD, Shaftel SS, Kyrkanides S, LaFerla FM, Olschowka JA, et al. Sustained interleukin-1 beta overexpression exacerbates tau pathology despite reduced amyloid burden in an Alzheimer's mouse model. J Neurosci. 2013;33(11):5053-64.

133. Liu Z, Condello C, Schain A, Harb R, Grutzendler J. CX3CR1 in microglia regulates brain amyloid deposition through selective protofibrillar amyloidbeta phagocytosis. J Neurosci. 2010;30(50):17091-101.

134. Lee S, Xu G, Jay TR, Bhatta S, Kim KW, Jung S, et al. Opposing effects of membrane-anchored CX3CL1 on amyloid and tau pathologies via the p38 MAPK pathway. J Neurosci. 2014;34(37):12538-46.

135. Petkau TL, Leavitt BR. Progranulin in neurodegenerative disease. Trends Neurosci. 2014;37(7):388-98.

136. Takahashi H, Klein ZA, Bhagat SM, Kaufman AC, Kostylev MA, Ikezu T, et al. Opposing effects of progranulin deficiency on amyloid and tau pathologies via microglial TYROBP network. Acta Neuropathol. 2017; 133(5):785-807.

137. Nelson PT, Alafuzoff I, Bigio EH, Bouras C, Braak H, Cairns NJ, et al. Correlation of Alzheimer disease neuropathologic changes with cognitive status: a review of the literature. J Neuropathol Exp Neurol. 2012;71(5):362-81.

138. Goddard CA, Butts DA, Shatz CJ. Regulation of CNS synapses by neuronal MHC class I. Proc Natl Acad Sci U S A. 2007;104(16):6828-33.

139. Lazarczyk MJ, Kemmler JE, Eyford BA, Short JA, Varghese M, Sowa A, et al. Major histocompatibility complex class I proteins are critical for maintaining neuronal structural complexity in the aging brain. Sci Rep. 2016;6:26199.

140. Fourgeaud L, Davenport CM, Tyler CM, Cheng TT, Spencer MB, Boulanger LM. MHC class I modulates NMDA receptor function and AMPA receptor trafficking. Proc Natl Acad Sci U S A. 2010;107(51):22278-83.
141. Prieto GA, Tong L, Smith ED, Cotman CW. TNFalpha and IL-1 beta but not IL18 suppresses hippocampal long-term potentiation directly at the synapse. Neurochem Res. 2018; https://doi.org/10.1007/s1 1064-018-2517-8. [Epub ahead of print]

142. Prieto GA, Snigdha S, Baglietto-Vargas D, Smith ED, Berchtold NC, Tong L, et al. Synapse-specific IL-1 receptor subunit reconfiguration augments vulnerability to IL-1 beta in the aged hippocampus. Proc Natl Acad Sci U S A. 2015;112(36):E5078-87.

143. Parkhurst CN, Yang G, Ninan I, Savas JN, Yates JR 3rd, Lafaille JJ, et al. Microglia promote learning-dependent synapse formation through brainderived neurotrophic factor. Cell. 2013;155(7):1596-609.

144. Zhan Y, Paolicelli RC, Sforazzini F, Weinhard L, Bolasco G, Pagani F, et al. Deficient neuron-microglia signaling results in impaired functional brain connectivity and social behavior. Nat Neurosci. 2014;17(3):400-6.

145. Schafer DP, Lehrman EK, Kautzman AG, Koyama R, Mardinly AR, Yamasaki R, et al. Microglia sculpt postnatal neural circuits in an activity and complement-dependent manner. Neuron. 2012;74(4):691-705.

146. Gautier EL, Shay T, Miller J, Greter M, Jakubzick C, Ivanov S, et al. Geneexpression profiles and transcriptional regulatory pathways that underlie the identity and diversity of mouse tissue macrophages. Nat Immunol. 2012; 13(11):1118-28.

147. Hong S, Beja-Glasser VF, Nfonoyim BM, Frouin A, Li S, Ramakrishnan S, et al. Complement and microglia mediate early synapse loss in Alzheimer mouse models. Science. 2016;352(6286):712-6.

148. Ma J, Choi BR, Chung C, Min SS, Jeon WK, Han JS. Chronic brain inflammation causes a reduction in GluN2A and GluN2B subunits of NMDA receptors and an increase in the phosphorylation of mitogenactivated protein kinases in the hippocampus. Mol Brain. 2014;7:33.

149. Liu $Y, X u X$, Dou H, Hua Y, Xu J, Hui X. Apolipoprotein E knockout induced inflammatory responses related to microglia in neonatal mice brain via astrocytes. Int J Clin Exp Med. 2015;8(1):737-43.

150. Sheng H, Laskowitz DT, Mackensen GB, Kudo M, Pearlstein RD, Warner DS. Apolipoprotein E deficiency worsens outcome from global cerebral ischemia in the mouse. Stroke. 1999:30(5):1118-24.

151. Lynch JR, Pineda JA, Morgan D, Zhang L, Warner DS, Benveniste $H$, et al. Apolipoprotein $\mathrm{E}$ affects the central nervous system response to injury and the development of cerebral edema. Ann Neurol. 2002;51(1):113-7.

152. Lynch JR, Morgan D, Mance J, Matthew WD, Laskowitz DT. Apolipoprotein E modulates glial activation and the endogenous central nervous system inflammatory response. J Neuroimmunol. 2001;114(1-2):107-13.

153. Guo L, LaDu MJ, Van Eldik LJ. A dual role for apolipoprotein e in neuroinflammation: anti- and pro-inflammatory activity. J Mol Neurosci. 2004:23(3):205-12

154. Vitek MP, Brown CM, Colton CA. APOE genotype-specific differences in the innate immune response. Neurobiol Aging. 2009;30(9):1350-60.

155. Zhu Y, Nwabuisi-Heath E, Dumanis SB, Tai LM, Yu C, Rebeck GW, et al. APOE genotype alters glial activation and loss of synaptic markers in mice. Glia. 2012;60(4):559-69

156. Rodriguez GA, Tai LM, LaDu MJ, Rebeck GW. Human APOE4 increases microglia reactivity at Abeta plaques in a mouse model of Abeta deposition. J Neuroinflammation. 2014;11:111.

157. den Hartigh $L$, Altman R, Hutchinson R, Petrlova J, Budamagunta MS, Tetali $\mathrm{SD}$, et al. Postprandial apoE isoform and conformational changes associated with VLDL lipolysis products modulate monocyte inflammation. PLoS One. 2012;7(11):e50513.

158. Gale SC, Gao L, Mikacenic C, Coyle SM, Rafaels N, Murray Dudenkov T, et al. APOepsilon4 is associated with enhanced in vivo innate immune responses in human subjects. J Allergy Clin Immunol. 2014;134(1):127-34.

159. Lynch JR, Tang W, Wang H, Vitek MP, Bennett ER, Sullivan PM, et al. APOE genotype and an ApoE-mimetic peptide modify the systemic and central nervous system inflammatory response. J Biol Chem. 2003;278(49):48529-33.

160. Maezawa I, Zaja-Milatovic S, Milatovic D, Stephen C, Sokal I, Maeda N, et al. Apolipoprotein $\mathrm{E}$ isoform-dependent dendritic recovery of hippocampal neurons following activation of innate immunity. J Neuroinflammation. 2006;3:21.

161. Rodriguez GA, Burns MP, Weeber EJ, Rebeck GW. Young APOE4 targeted replacement mice exhibit poor spatial learning and memory, with reduced dendritic spine density in the medial entorhinal cortex. Learn Mem. 2013; 20(5):256-66.

162. Terwel D, Steffensen KR, Verghese PB, Kummer MP, Gustafsson JA, Holtzman $D M$, et al. Critical role of astroglial apolipoprotein $E$ and liver $X$ receptor- 
alpha expression for microglial Abeta phagocytosis. J Neurosci. 2011;31(19): 7049-59.

163. Atagi Y, Liu CC, Painter MM, Chen XF, Verbeeck C, Zheng $H$, et al. Apolipoprotein $\mathrm{E}$ is a ligand for triggering receptor expressed on myeloid cells 2 (TREM2). J Biol Chem. 2015;290(43):26043-50.

164. Krasemann S, Madore C, Cialic R, Baufeld C, Calcagno N, El Fatimy R, et al. The TREM2-APOE pathway drives the transcriptional phenotype of dysfunctional microglia in neurodegenerative diseases. Immunity. 2017; 47(3):566-81 e9.

165. Guerreiro R, Wojtas A, Bras J, Carrasquillo M, Rogaeva E, Majounie E, et al. TREM2 variants in Alzheimer's disease. N Engl J Med. 2013;368(2):117-27.

166. Cruchaga C, Kauwe JS, Harari O, Jin SC, Cai Y, Karch CM, et al. GWAS of cerebrospinal fluid tau levels identifies risk variants for Alzheimer's disease. Neuron. 2013;78(2):256-68.

167. Kleinberger G, Yamanishi Y, Suarez-Calvet M, Czirr E, Lohmann E, Cuyvers E, et al. TREM2 mutations implicated in neurodegeneration impair cell surface transport and phagocytosis. Sci Transl Med. 2014;6(243):243ra86.

168. Daws MR, Sullam PM, Niemi EC, Chen TT, Tchao NK, Seaman WE. Pattern recognition by TREM-2: binding of anionic ligands. J Immunol. 2003;171(2): 594-9.

169. Kobayashi M, Konishi H, Sayo A, Takai T, Kiyama H. TREM2/DAP12 signal elicits proinflammatory response in microglia and exacerbates neuropathic pain. J Neurosci. 2016;36(43):11138-50.

170. Zhao Y, Wu X, Li X, Jiang LL, Gui X, Liu Y, et al. TREM2 is a receptor for betaamyloid that mediates microglial function. Neuron. 2018;97(5):1023-31 e7.

171. Bouchon A, Hernandez-Munain C, Cella M, Colonna M. A DAP12-mediated pathway regulates expression of CC chemokine receptor 7 and maturation of human dendritic cells. J Exp Med. 2001;194(8):1111-22.

172. Ito H, Hamerman JA. TREM-2, triggering receptor expressed on myeloid cell2 , negatively regulates TLR responses in dendritic cells. Eur J Immunol. 2012; 42(1):176-85.

173. Zhong L, Chen XF, Wang T, Wang Z, Liao C, Wang Z, et al. Soluble TREM2 induces inflammatory responses and enhances microglial survival. J Exp Med. 2017;214(3):597-607.

174. Heslegrave A, Heywood W, Paterson R, Magdalinou N, Svensson J, Johansson $P$, et al. Increased cerebrospinal fluid soluble TREM2 concentration in Alzheimer's disease. Mol Neurodegener. 2016;11:3.

175. Suarez-Calvet M, Kleinberger G, Araque Caballero MA, Brendel M, Rominger A, Alcolea D, et al. sTREM2 cerebrospinal fluid levels are a potential biomarker for microglia activity in early-stage Alzheimer's disease and associate with neuronal injury markers. EMBO Mol Med. 2016;8(5):466-76.

176. Kober DL, Alexander-Brett JM, Karch CM, Cruchaga C, Colonna M, Holtzman MJ, et al. Neurodegenerative disease mutations in TREM2 reveal a functional surface and distinct loss-of-function mechanisms. elife. 2016;5:e20391.

177. Jonsson T, Stefansson H, Steinberg S, Jonsdottir I, Jonsson PV, Snaedal J, et al. Variant of TREM2 associated with the risk of Alzheimer's disease. N Engl J Med. 2013;368(2):107-16.

178. Mazaheri F, Snaidero N, Kleinberger G, Madore C, Daria A, Werner G, et al. TREM2 deficiency impairs chemotaxis and microglial responses to neuronal injury. EMBO Rep. 2017;18(7):1186-98.

179. Cheng Q, Danao J, Talreja S, Wen P, Yin J, Sun N, et al. TREM2-activating antibodies abrogate the negative pleiotropic effects of the Alzheimer's disease variant TREM2(R47H) on murine myeloid cell function. J Biol Chem. 2018;293(32):12620-33.

180. Yeh FL, Wang Y, Tom I, Gonzalez LC, Sheng M. TREM2 binds to apolipoproteins, including APOE and CLU/APOJ, and thereby facilitates uptake of amyloid-Beta by microglia. Neuron. 2016;91(2):328-40.

181. Jay TR, Hirsch AM, Broihier ML, Miller CM, Neilson LE, Ransohoff RM, et al. Disease progression-dependent effects of TREM2 deficiency in a mouse model of Alzheimer's disease. J Neurosci. 2017;37(3):637-47.

182. Jiang T, Tan L, Zhu XC, Zhang QQ, Cao L, Tan MS, et al. Upregulation of TREM2 ameliorates neuropathology and rescues spatial cognitive impairment in a transgenic mouse model of Alzheimer's disease. Neuropsychopharmacology. 2014;39(13):2949-62.

183. Haure-Mirande JV, Audrain M, Fanutza T, Kim SH, Klein WL, Glabe C, et al. Deficiency of TYROBP, an adapter protein for TREM2 and CR3 receptors, is neuroprotective in a mouse model of early Alzheimer's pathology. Acta Neuropathol. 2017;134(5):769-88.

184. Kim SM, Mun BR, Lee SJ, Joh Y, Lee HY, Ji KY, et al. TREM2 promotes Abeta phagocytosis by upregulating C/EBPalpha-dependent CD36 expression in microglia. Sci Rep. 2017;7(1):11118.
185. Hamerman JA, Jarjoura JR, Humphrey MB, Nakamura MC, Seaman WE Lanier LL. Cutting edge: inhibition of TLR and FCR responses in macrophages by triggering receptor expressed on myeloid cells (TREM)-2 and DAP12. J Immunol. 2006;177(4):2051-5.

186. Bemiller SM, McCray TJ, Allan K, Formica SV, Xu G, Wilson G, et al. TREM2 deficiency exacerbates tau pathology through dysregulated kinase signaling in a mouse model of tauopathy. Mol Neurodegener. 2017;12(1):74.

187. Leyns CEG, Ulrich JD, Finn MB, Stewart FR, Koscal LJ, Remolina Serrano J, et al. TREM2 deficiency attenuates neuroinflammation and protects against neurodegeneration in a mouse model of tauopathy. Proc Natl Acad Sci U S A. 2017;114(43):11524-9.

188. Jiang T, Zhang YD, Gao Q, Ou Z, Gong PY, Shi JQ, et al. TREM2 ameliorates neuronal tau pathology through suppression of microglial inflammatory response. Inflammation. 2018;41(3):811-23.

189. Ulyanova T, Blasioli J, Woodford-Thomas TA, Thomas ML. The sialoadhesin CD33 is a myeloid-specific inhibitory receptor. Eur J Immunol. 1999;29(11): 3440-9.

190. Lajaunias F, Dayer JM, Chizzolini C. Constitutive repressor activity of CD33 on human monocytes requires sialic acid recognition and phosphoinositide 3-kinase-mediated intracellular signaling. Eur J Immunol. 2005;35(1):243-51.

191. Gonzalez Y, Herrera MT, Soldevila G, Garcia-Garcia L, Fabian G, PerezArmendariz EM, et al. High glucose concentrations induce TNF-alpha production through the down-regulation of CD33 in primary human monocytes. BMC Immunol. 2012;13:19.

192. Bertram L, Lange C, Mullin K, Parkinson M, Hsiao M, Hogan MF, et al. Genome-wide association analysis reveals putative Alzheimer's disease susceptibility loci in addition to APOE. Am J Hum Genet. 2008;83(5):623-32.

193. Karch CM, Jeng AT, Nowotny P, Cady J, Cruchaga C, Goate AM. Expression of novel Alzheimer's disease risk genes in control and Alzheimer's disease brains. PLoS One. 2012;7(11):e50976.

194. Bradshaw EM, Chibnik LB, Keenan BT, Ottoboni L, Raj T, Tang A, et al. CD33 Alzheimer's disease locus: altered monocyte function and amyloid biology. Nat Neurosci. 2013;16(7):848-50.

195. Raj T, Ryan KJ, Replogle JM, Chibnik LB, Rosenkrantz L, Tang A, et al. CD33: increased inclusion of exon 2 implicates the $\lg$ V-set domain in Alzheimer's disease susceptibility. Hum Mol Genet. 2014;23(10):2729-36.

196. Naj AC, Jun G, Beecham GW, Wang LS, Vardarajan BN, Buros J, et al. Common variants at MS4A4/MS4A6E, CD2AP, CD33 and EPHA1 are associated with late-onset Alzheimer's disease. Nat Genet. 2011;43(5):436-41.

197. Malik M, Simpson JF, Parikh I, Wilfred BR, Fardo DW, Nelson PT, et al. CD33 Alzheimer's risk-altering polymorphism, CD33 expression, and exon 2 splicing. J Neurosci. 2013;33(33):13320-5.

198. Griciuc A, Serrano-Pozo A, Parrado AR, Lesinski AN, Asselin CN, Mullin K, et al. Alzheimer's disease risk gene CD33 inhibits microglial uptake of amyloid beta. Neuron. 2013;78(4):631-43.

199. Walker DG, Whetzel AM, Serrano G, Sue LI, Beach TG, Lue LF. Association of CD33 polymorphism rs3865444 with Alzheimer's disease pathology and CD33 expression in human cerebral cortex. Neurobiol Aging. 2015;36(2): 571-82.

200. Chan G, White CC, Winn PA, Cimpean M, Replogle JM, Glick LR, et al. CD33 modulates TREM2: convergence of Alzheimer loci. Nat Neurosci. 2015;18(11): 1556-8.

201. Caldeira C, Cunha C, Vaz AR, Falcao AS, Barateiro A, Seixas E, et al. Key aging-associated alterations in primary microglia response to Beta-amyloid stimulation. Front Aging Neurosci. 2017:9:277.

202. Walker JM, Harrison FE. Shared neuropathological characteristics of obesity, type 2 diabetes and Alzheimer's disease: impacts on cognitive decline. Nutrients. 2015;7(9):7332-57.

203. Arvanitakis Z, Wilson RS, Bienias JL, Evans DA, Bennett DA. Diabetes mellitus and risk of Alzheimer disease and decline in cognitive function. Arch Neurol. 2004;61(5):661-6

204. Li JQ, Tan L, Wang HF, Tan MS, Tan L, Xu W, et al. Risk factors for predicting progression from mild cognitive impairment to Alzheimer's disease: a systematic review and meta-analysis of cohort studies. J Neurol Neurosurg Psychiatry. 2016;87(5):476-84

205. Yamamoto N, Matsubara T, Sobue K, Tanida M, Kasahara R, Naruse K, et al. Brain insulin resistance accelerates Abeta fibrillogenesis by inducing GM1 ganglioside clustering in the presynaptic membranes. J Neurochem. 2012 121(4):619-28.

206. Stanley M, Macauley SL, Caesar EE, Koscal LJ, Moritz W, Robinson GO, et al. The effects of peripheral and central high insulin on brain insulin signaling 
and amyloid-beta in young and old APP/PS1 mice. J Neurosci. 2016;36(46): 11704-15.

207. Farris W, Mansourian S, Chang Y, Lindsley L, Eckman EA, Frosch MP, et al. Insulin-degrading enzyme regulates the levels of insulin, amyloid betaprotein, and the beta-amyloid precursor protein intracellular domain in vivo. Proc Natl Acad Sci U S A. 2003;100(7):4162-7.

208. Kim B, Figueroa-Romero C, Pacut C, Backus C, Feldman EL. Insulin resistance prevents AMPK-induced tau dephosphorylation through Aktmediated increase in AMPKSer-485 phosphorylation. J Biol Chem. 2015; 290(31):19146-57.

209. Spolcova A, Mikulaskova B, Krskova K, Gajdosechova L, Zorad S, Olszanecki $R$, et al. Deficient hippocampal insulin signaling and augmented tau phosphorylation is related to obesity- and age-induced peripheral insulin resistance: a study in Zucker rats. BMC Neurosci. 2014;15:111.

210. Park S, Kim DS, Kang S, Moon NR. Beta-amyloid-induced cognitive dysfunction impairs glucose homeostasis by increasing insulin resistance and decreasing beta-cell mass in non-diabetic and diabetic rats. Metabolism. 2013;62(12):1749-60.

211. Moser VA, Pike CJ. Obesity accelerates Alzheimer-related pathology in APOE4 but not APOE3 mice. eNeuro. 2017;4(3):ENEURO.0077-17.2017.

212. Johnson LA, Torres ER, Weber Boutros S, Patel E, Akinyeke T, Alkayed NJ, et al. Apolipoprotein E4 mediates insulin resistance-associated cerebrovascular dysfunction and the post-prandial response. J Cereb Blood Flow Metab. 2017;1:271678X17746186.

213. Mustain WC, Starr ME, Valentino JD, Cohen DA, Okamura D, Wang C, et al. Inflammatory cytokine gene expression in mesenteric adipose tissue during acute experimental colitis. PLoS One. 2013;8(12):e83693.

214. Haghani K, Pashaei S, Vakili S, Taheripak G, Bakhtiyari S. TNF-alpha knockdown alleviates palmitate-induced insulin resistance in $\mathrm{C} 2 \mathrm{C} 12$ skeletal muscle cells. Biochem Biophys Res Commun. 2015;460(4):977-82.

215. Weisberg SP, McCann D, Desai M, Rosenbaum M, Leibel RL, Ferrante AW Jr. Obesity is associated with macrophage accumulation in adipose tissue. J Clin Invest. 2003;112(12):1796-808.

216. Cortez M, Carmo LS, Rogero MM, Borelli P, Fock RA. A high-fat diet increases IL-1, IL-6, and TNF-alpha production by increasing NF-kappaB and attenuating PPAR-gamma expression in bone marrow mesenchymal stem cells. Inflammation. 2013;36(2):379-86.

217. Lukic L, Lalic NM, Rajkovic N, Jotic A, Lalic K, Milicic T, et al. Hypertension in obese type 2 diabetes patients is associated with increases in insulin resistance and IL-6 cytokine levels: potential targets for an efficient preventive intervention. Int J Environ Res Public Health. 2014;11(4):3586-98.

218. van der Heijden RA, Sheedfar F, Morrison MC, Hommelberg PP, Kor D, Kloosterhuis NJ, et al. High-fat diet induced obesity primes inflammation in adipose tissue prior to liver in C57BL/6j mice. Aging (Albany NY). 2015;7(4): 256-68.

219. Gao M, Ma Y, Liu D. High-fat diet-induced adiposity, adipose inflammation, hepatic steatosis and hyperinsulinemia in outbred CD-1 mice. PLoS One. 2015;10(3):e0119784.

220. Lee HM, Kim JJ, Kim HJ, Shong M, Ku BJ, Jo EK. Upregulated NLRP3 inflammasome activation in patients with type 2 diabetes. Diabetes. 2013; 62(1):194-204.

221. McKie EA, Reid JL, Mistry PC, DeWall SL, Abberley L, Ambery PD, et al. A study to investigate the efficacy and safety of an anti-Interleukin-18 monoclonal antibody in the treatment of type 2 diabetes mellitus. PLoS One. 2016;11(3):e0150018.

222. Lenart N, Brough D, Denes A. Inflammasomes link vascular disease with neuroinflammation and brain disorders. J Cereb Blood Flow Metab. 2016; 36(10):1668-85.

223. Hou HW, Petchakup C, Tay HM, Tam ZY, Dalan R, Chew DE, et al. Rapid and label-free microfluidic neutrophil purification and phenotyping in diabetes mellitus. Sci Rep. 2016;6:29410.

224. Horvath P, Oliver SR, Ganesan G, Zaldivar FP Jr, Radom-Aizik S, Galassetti PR. Fasting glucose level modulates cell surface expression of CD11b and CD66b in granulocytes and monocytes of patients with type 2 diabetes. J Investig Med. 2013;61(6):972-7.

225. Dasu MR, Jialal I. Free fatty acids in the presence of high glucose amplify monocyte inflammation via toll-like receptors. Am J Physiol Endocrinol Metab. 2011;300(1):E145-54.

226. Gupta S, Maratha A, Siednienko J, Natarajan A, Gajanayake T, Hoashi S, et al. Analysis of inflammatory cytokine and TLR expression levels in type 2 diabetes with complications. Sci Rep. 2017;7(1):7633.
227. Copps KD, White MF. Regulation of insulin sensitivity by serine/threonine phosphorylation of insulin receptor substrate proteins IRS1 and IRS2. Diabetologia. 2012;55(10):2565-82.

228. Chen L, Chen R, Wang H, Liang F. Mechanisms linking inflammation to insulin resistance. Int J Endocrinol. 2015;2015:508409.

229. Koenen TB, Stienstra R, van Tits LJ, de Graaf J, Stalenhoef AF, Joosten LA, et al. Hyperglycemia activates caspase-1 and TXNIP-mediated IL-1 beta transcription in human adipose tissue. Diabetes. 2011;60(2):517-24.

230. Su D, Coudriet GM, Hyun Kim D, Lu Y, Perdomo G, Qu S, et al. FoxO1 links insulin resistance to proinflammatory cytokine IL-1beta production in macrophages. Diabetes. 2009;58(11):2624-33.

231. Dhande I, Ma W, Hussain T. Angiotensin AT2 receptor stimulation is antiinflammatory in lipopolysaccharide-activated THP-1 macrophages via increased interleukin-10 production. Hypertens Res. 2015;38(1):21-9.

232. Feinkohl I, Keller M, Robertson CM, Morling JR, McLachlan S, Frier BM, et al. Cardiovascular risk factors and cognitive decline in older people with type 2 diabetes. Diabetologia. 2015;58(7):1637-45.

233. Feinkohl I, Keller M, Robertson CM, Morling JR, Williamson RM, Nee LD, et al. Clinical and subclinical macrovascular disease as predictors of cognitive decline in older patients with type 2 diabetes: the Edinburgh Type 2 Diabetes Study. Diabetes Care. 2013;36(9):2779-86.

234. Umegaki H, Kawamura T, Umemura T, Kawano N. Factors associated with cognitive decline in older adults with type 2 diabetes mellitus during a 6year observation. Geriatr Gerontol Int. 2015;15(3):302-10.

235. van Bussel FC, Backes WH, Hofman PA, Puts NA, Edden RA, van Boxtel MP, et al. Increased GABA concentrations in type 2 diabetes mellitus are related to lower cognitive functioning. Medicine (Baltimore). 2016;95(36):e4803.

236. Tucsek Z, Noa Valcarcel-Ares M, Tarantini S, Yabluchanskiy A, Fulop G, Gautam T, et al. Hypertension-induced synapse loss and impairment in synaptic plasticity in the mouse hippocampus mimics the aging phenotype: implications for the pathogenesis of vascular cognitive impairment. Geroscience. 2017; https:/doi. org/10.1007/s11357-017-9981-y. [Epub ahead of print]

237. Bocarsly ME, Fasolino M, Kane GA, LaMarca EA, Kirschen GW, Karatsoreos IN, et al. Obesity diminishes synaptic markers, alters microglial morphology, and impairs cognitive function. Proc Natl Acad Sci U S A. 2015;112(51): $15731-6$.

238. Hao S, Dey A, Yu X, Stranahan AM. Dietary obesity reversibly induces synaptic stripping by microglia and impairs hippocampal plasticity. Brain Behav Immun. 2016;51:230-9.

239. Faden Al, Loane DJ. Chronic neurodegeneration after traumatic brain injury: Alzheimer disease, chronic traumatic encephalopathy, or persistent neuroinflammation? Neurotherapeutics. 2015;12(1):143-50.

240. Dams-O'Connor K, Guetta G, Hahn-Ketter AE, Fedor A. Traumatic brain injury as a risk factor for Alzheimer's disease: current knowledge and future directions. Neurodegener Dis Manag. 2016;6(5):417-29.

241. DeKosky ST, Abrahamson EE, Ciallella JR, Paljug WR, Wisniewski SR, Clark RS, et al. Association of increased cortical soluble abeta42 levels with diffuse plaques after severe brain injury in humans. Arch Neurol. 2007;64(4):541-4.

242. Gentleman SM, Greenberg BD, Savage MJ, Noori M, Newman SJ, Roberts GW, et al. A beta 42 is the predominant form of amyloid beta-protein in the brains of short-term survivors of head injury. Neuroreport. 1997;8(6):1519-22.

243. Johnson VE, Stewart W, Smith DH. Widespread tau and amyloid-beta pathology many years after a single traumatic brain injury in humans. Brain Pathol. 2012;22(2):142-9.

244. Acosta SA, Tajiri N, Sanberg PR, Kaneko Y, Borlongan CV. Increased amyloid precursor protein and tau expression manifests as key secondary cell death in chronic traumatic brain injury. J Cell Physiol. 2017;232(3):665-77.

245. Corrigan F, Vink R, Blumbergs PC, Masters CL, Cappai R, van den Heuvel C. Characterisation of the effect of knockout of the amyloid precursor protein on outcome following mild traumatic brain injury. Brain Res. 2012;1451:87-99.

246. Thornton E, Vink R, Blumbergs PC, Van Den Heuvel C. Soluble amyloid precursor protein alpha reduces neuronal injury and improves functional outcome following diffuse traumatic brain injury in rats. Brain Res. 2006; 1094(1):38-46.

247. Plummer S, Van den Heuvel C, Thornton E, Corrigan F, Cappai R. The neuroprotective properties of the amyloid precursor protein following traumatic brain injury. Aging Dis. 2016;7(2):163-79.

248. Roth TL, Nayak D, Atanasijevic T, Koretsky AP, Latour LL, McGavern DB. Transcranial amelioration of inflammation and cell death after brain injury. Nature. 2014;505(7482):223-8. 
249. Corps KN, Roth TL, McGavern DB. Inflammation and neuroprotection in traumatic brain injury. JAMA Neurol. 2015;72(3):355-62.

250. Das M, Mohapatra S, Mohapatra SS. New perspectives on central and peripheral immune responses to acute traumatic brain injury. J Neuroinflammation. 2012;9:236.

251. Hinson HE, Rowell S, Schreiber M. Clinical evidence of inflammation driving secondary brain injury: a systematic review. J Trauma Acute Care Surg. 2015; 78(1):184-91.

252. Gao H, Han Z, Bai R, Huang S, Ge X, Chen F, et al. The accumulation of brain injury leads to severe neuropathological and neurobehavioral changes after repetitive mild traumatic brain injury. Brain Res. 2017;1657:1-8.

253. Liu HD, Li W, Chen ZR, Hu YC, Zhang DD, Shen W, et al. Expression of the NLRP3 inflammasome in cerebral cortex after traumatic brain injury in a rat model. Neurochem Res. 2013;38(10):2072-83.

254. Gorina R, Font-Nieves M, Marquez-Kisinousky L, Santalucia T, Planas AM. Astrocyte TLR4 activation induces a proinflammatory environment through the interplay between MyD88-dependent NFkappaB signaling, MAPK, and Jak1/Stat1 pathways. Glia. 2011;59(2):242-55.

255. Jayakumar AR, Tong XY, Ruiz-Cordero R, Bregy A, Bethea JR, Bramlett HM, et al. Activation of NF-kappaB mediates astrocyte swelling and brain edema in traumatic brain injury. J Neurotrauma. 2014;31(14): 1249-57.

256. Hayakawa K, Pham LD, Katusic ZS, Arai K, Lo EH. Astrocytic high-mobility group box 1 promotes endothelial progenitor cell-mediated neurovascula remodeling during stroke recovery. Proc Natl Acad Sci U S A. 2012;109(19): 7505-10.

257. Argaw AT, Gurfein BT, Zhang Y, Zameer A, John GR. VEGF-mediated disruption of endothelial CLN-5 promotes blood-brain barrier breakdown. Proc Natl Acad Sci U S A. 2009;106(6):1977-82

258. Mark KS, Miller DW. Increased permeability of primary cultured brain microvessel endothelial cell monolayers following TNF-alpha exposure. Life Sci. 1999;64(21):1941-53.

259. Wojciak-Stothard B, Entwistle A, Garg R, Ridley AJ. Regulation of TNF-alphainduced reorganization of the actin cytoskeleton and cell-cell junctions by rho, Rac, and Cdc42 in human endothelial cells. J Cell Physiol. 1998;176(1): 150-65.

260. Shaftel SS, Carlson TJ, Olschowka JA, Kyrkanides S, Matousek SB, O'Banion MK. Chronic interleukin-1beta expression in mouse brain leads to leukocyte infiltration and neutrophil-independent blood brain barrier permeability without overt neurodegeneration. J Neurosci. 2007;27(35):9301-9.

261. Semple BD, Bye N, Ziebell JM, Morganti-Kossmann MC. Deficiency of the chemokine receptor CXCR2 attenuates neutrophil infiltration and cortical damage following closed head injury. Neurobiol Dis. 2010;40(2):394-403.

262. Semple BD, Bye N, Rancan M, Ziebell JM, Morganti-Kossmann MC. Role of CCL2 (MCP-1) in traumatic brain injury (TBI): evidence from severe TBI patients and CCL2-/- mice. J Cereb Blood Flow Metab. 2010;30(4):769-82.

263. Huang J, Li Y, Tang Y, Tang G, Yang GY, Wang Y. CXCR4 antagonist AMD3100 protects blood-brain barrier integrity and reduces inflammatory response after focal ischemia in mice. Stroke. 2013:44(1):190-7.

264. Kong LL, Wang ZY, Hu JF, Yuan YH, Li H, Chen NH. Inhibition of chemokinelike factor 1 improves blood-brain barrier dysfunction in rats following focal cerebral ischemia. Neurosci Lett. 2016;627:192-8.

265. Szmydynger-Chodobska J, Fox LM, Lynch KM, Zink BJ, Chodobski A. Vasopressin amplifies the production of proinflammatory mediators in traumatic brain injury. J Neurotrauma. 2010;27(8):1449-61.

266. Mirabelli-Badenier M, Braunersreuther V, Viviani GL, Dallegri F, Quercioli A, Veneselli $E$, et al. CC and CXC chemokines are pivotal mediators of cerebral injury in ischaemic stroke. Thromb Haemost. 2011;105(3):409-20.

267. Kenne E, Erlandsson A, Lindbom L, Hillered L, Clausen F. Neutrophil depletion reduces edema formation and tissue loss following traumatic brain injury in mice. J Neuroinflammation. 2012;9:17.

268. Makinde HM, Cuda CM, Just TB, Perlman HR, Schwulst SJ. Nonclassical monocytes mediate secondary injury, neurocognitive outcome, and neutrophil infiltration after traumatic brain injury. J Immunol. 2017;199(10): 3583-91.

269. Nagata K, Browne KD, Suto Y, Kumasaka K, Cognetti J, Johnson VE, et al. Early heparin administration after traumatic brain injury: prolonged cognitive recovery associated with reduced cerebral edema and neutrophil sequestration. J Trauma Acute Care Surg. 2017;83(3):406-12.

270. Ponsford J, McLaren A, Schonberger M, Burke R, Rudzki D, Olver J, et al. The association between apolipoprotein $\mathrm{E}$ and traumatic brain injury severity and functional outcome in a rehabilitation sample. J Neurotrauma. 2011; 28(9):1683-92

271. Cao J, Gaamouch FE, Meabon JS, Meeker KD, Zhu L, Zhong MB, et al. ApoE4associated phospholipid dysregulation contributes to development of tau hyper-phosphorylation after traumatic brain injury. Sci Rep. 2017;7(1):11372.

272. Castranio EL, Mounier A, Wolfe CM, Nam KN, Fitz NF, Letronne F, et al. Gene co-expression networks identify Trem2 and Tyrobp as major hubs in human APOE expressing mice following traumatic brain injury. Neurobiol Dis. 2017; 105:1-14.

273. Sundstrom A, Nilsson LG, Cruts M, Adolfsson R, Van Broeckhoven C, Nyberg $L$. Increased risk of dementia following mild head injury for carriers but not for non-carriers of the APOE epsilon4 allele. Int Psychogeriatr. 2007;19(1): 159-65.

274. Dams-O'Connor K, Gibbons LE, Bowen JD, McCurry SM, Larson EB, Crane PK. Risk for late-life re-injury, dementia and death among individuals with traumatic brain injury: a population-based study. J Neurol Neurosurg Psychiatry. 2013;84(2):177-82.

275. Friedland RP, Chapman MR. The role of microbial amyloid in neurodegeneration. PLoS Pathog. 2017;13(12):e1006654

276. Claesson MJ, Cusack S, O'Sullivan O, Greene-Diniz R, de Weerd H, Flannery E, et al. Composition, variability, and temporal stability of the intestinal microbiota of the elderly. Proc Natl Acad Sci U S A. 2011;108(Suppl 1):4586-91.

277. Biagi E, Nylund L, Candela M, Ostan R, Bucci L, Pini E, et al. Through ageing, and beyond: gut microbiota and inflammatory status in seniors and centenarians. PLoS One. 2010;5(5):e10667.

278. Claesson MJ, Jeffery IB, Conde S, Power SE, O'Connor EM, Cusack S, et al. Gut microbiota composition correlates with diet and health in the elderly. Nature. 2012;488(7410):178-84

279. Calabrese V, Santoro A, Monti D, Crupi R, Di Paola R, Latteri S, et al. Aging and Parkinson's disease: Inflammaging, neuroinflammation and biological remodeling as key factors in pathogenesis. Free Radic Biol Med. 2018;115: 80-91.

280. Scott KA, Ida M, Peterson VL, Prenderville JA, Moloney GM, Izumo T, et al. Revisiting Metchnikoff: age-related alterations in microbiota-gut-brain axis in the mouse. Brain Behav Immun. 2017;65:20-32.

281. Deleidi M, Jaggle M, Rubino G. Immune aging, dysmetabolism, and inflammation in neurological diseases. Front Neurosci. 2015;9:172.

282. Fransen F, van Beek AA, Borghuis T, Aidy SE, Hugenholtz F, van der Gaastde Jongh $C$, et al. Aged gut microbiota contributes to systemical inflammaging after transfer to germ-free mice. Front Immunol. 2017:8:1385.

283. Cekanaviciute E, Yoo BB, Runia TF, Debelius JW, Singh S, Nelson CA, et al. Gut bacteria from multiple sclerosis patients modulate human T cells and exacerbate symptoms in mouse models. Proc Natl Acad Sci U S A. 2017; 114(40):10713-8.

284. Naseer MI, Bibi F, Alqahtani MH, Chaudhary AG, Azhar El, Kamal MA, et al. Role of gut microbiota in obesity, type 2 diabetes and Alzheimer's disease. CNS Neurol Disord Drug Targets. 2014;13(2):305-11.

285. Zhao L, Zhang F, Ding X, Wu G, Lam YY, Wang X, et al. Gut bacteria selectively promoted by dietary fibers alleviate type 2 diabetes. Science. 2018;359(6380):1151-6.

286. Beli E, Yan Y, Moldovan L, Vieira CP, Gao R, Duan Y, et al. Restructuring of the gut microbiome by intermittent fasting prevents retinopathy and prolongs survival in db/db mice. Diabetes. 2018;67(9):1867-79.

287. Bangasser DA, Dong H, Carroll J, Plona Z, Ding H, Rodriguez L, et al. Corticotropin-releasing factor overexpression gives rise to sex differences in Alzheimer's disease-related signaling. Mol Psychiatry. 2017;22(8):1126-33.

288. Gao X, Cao Q, Cheng Y, Zhao D, Wang Z, Yang H, et al. Chronic stress promotes colitis by disturbing the gut microbiota and triggering immune system response. Proc Natl Acad Sci U S A. 2018;115(13):E2960-E9.

289. Wang T, Hu X, Liang S, Li W, Wu X, Wang L, et al. Lactobacillus fermentum NS9 restores the antibiotic induced physiological and psychological abnormalities in rats. Benef Microbes. 2015;6(5):707-17.

290. Gareau MG, Wine E, Rodrigues DM, Cho JH, Whary MT, Philpott DJ, et al. Bacterial infection causes stress-induced memory dysfunction in mice. Gut. 2011;60(3):307-17

291. Bruce-Keller AJ, Salbaum JM, Luo M, Et B, Taylor CM, Welsh DA, et al. Obesetype gut microbiota induce neurobehavioral changes in the absence of obesity. Biol Psychiatry. 2015;77(7):607-15.

292. Vogt NM, Kerby RL, Dill-McFarland KA, Harding SJ, Merluzzi AP, Johnson SC, et al. Gut microbiome alterations in Alzheimer's disease. Sci Rep. $2017 ; 7(1): 13537$ 
293. Cattaneo A, Cattane N, Galluzzi S, Provasi S, Lopizzo N, Festari C, et al. Association of brain amyloidosis with pro-inflammatory gut bacterial taxa and peripheral inflammation markers in cognitively impaired elderly. Neurobiol Aging. 2017:49:60-8.

294. Harach T, Marungruang N, Duthilleul N, Cheatham V, Mc Coy KD, Frisoni G, et al. Reduction of Abeta amyloid pathology in APPPS1 transgenic mice in the absence of gut microbiota. Sci Rep. 2017;7:41802.

295. Everard A, Belzer C, Geurts L, Ouwerkerk JP, Druart C, Bindels LB, et al. Crosstalk between Akkermansia muciniphila and intestinal epithelium controls diet-induced obesity. Proc Natl Acad Sci U S A. 2013;110(22):9066-71.

296. Minter MR, Hinterleitner R, Meisel M, Zhang C, Leone V, Zhang X, et al Antibiotic-induced perturbations in microbial diversity during post-natal development alters amyloid pathology in an aged APPSWE/PS1DeltaE9 murine model of Alzheimer's disease. Sci Rep. 2017;7(1):10411.

297. Brandscheid C, Schuck F, Reinhardt S, Schafer KH, Pietrzik CU, Grimm M, et al. Altered gut microbiome composition and tryptic activity of the 5xFAD Alzheimer's mouse model. J Alzheimers Dis. 2017:56(2):775-88.

298. Kell DB, Pretorius E. On the translocation of bacteria and their lipopolysaccharides between blood and peripheral locations in chronic, inflammatory diseases: the central roles of LPS and LPSinduced cell death. Integr Biol (Camb). 2015;7(11):1339-77.

299. Asti A, Gioglio L. Can a bacterial endotoxin be a key factor in the kinetics of amyloid fibril formation? J Alzheimers Dis. 2014;39(1):169-79.

300. Kahn MS, Kranjac D, Alonzo CA, Haase JH, Cedillos RO, McLinden KA, et al. Prolonged elevation in hippocampal Abeta and cognitive deficits following repeated endotoxin exposure in the mouse. Behav Brain Res. 2012;229(1): $176-84$.

301. Zhan X, Stamova B, Jin LW, DeCarli C, Phinney B, Sharp FR. Gram-negative bacterial molecules associate with Alzheimer disease pathology. Neurology. 2016;87(22):2324-32

302. Zhao Y, Jaber $V$, Lukiw WJ. Secretory products of the human Gl tract microbiome and their potential impact on Alzheimer's disease (AD): detection of lipopolysaccharide (LPS) in AD Hippocampus. Front Cell Infect Microbiol. 2017;7:318.

303. Distrutti E, O'Reilly JA, McDonald C, Cipriani S, Renga B, Lynch MA, et al. Modulation of intestinal microbiota by the probiotic VSL\#3 resets brain gene expression and ameliorates the age-related deficit in LTP. PLOS One. 2014;9(9):e106503.

304. Alkasir R, Li J, Li X, Jin M, Zhu B. Human gut microbiota: the links with dementia development. Protein Cell. 2017:8(2):90-102.

305. Walker JM, Dixit S, Saulsberry AC, May JM, Harrison FE. Reversal of high fat diet-induced obesity improves glucose tolerance, inflammatory response, beta-amyloid accumulation and cognitive decline in the APP/PSEN1 mouse model of Alzheimer's disease. Neurobiol Dis. 2017;100:87-98.

306. Wiesmann M, Jansen D, Zerbi V, Broersen LM, Garthe A, Kiliaan AJ. Improved spatial learning strategy and memory in aged Alzheimer AbetaPPswe/ PS1dE9 mice on a multi-nutrient diet. J Alzheimers Dis. 2013;37(1):233-45.

307. Kim SE, Ko IG, Shin MS, Kim CJ, Jin BK, Hong HP, et al. Treadmill exercise and wheel exercise enhance expressions of neutrophic factors in the hippocampus of lipopolysaccharide-injected rats. Neurosci Lett. 2013;538: 54-9.

308. Dallagnol KMC, Remor AP, da Silva RA, Prediger RD, Latini A, Aguiar AS Jr. Running for REST: physical activity attenuates neuroinflammation in the hippocampus of aged mice. Brain Behav Immun. 2017;61:31-5.

309. Souza LC, Jesse CR, Del Fabbro L, de Gomes MG, ATR G, Filho CB, et al. Swimming exercise prevents behavioural disturbances induced by an intracerebroventricular injection of amyloid-beta1-42 peptide through modulation of cytokine/NF-kappaB pathway and indoleamine-2,3dioxygenase in mouse brain. Behav Brain Res. 2017;331:1-13.

310. Do K, Laing BT, Landry T, Bunner W, Mersaud N, Matsubara T, et al. The effects of exercise on hypothalamic neurodegeneration of Alzheimer's disease mouse model. PLoS One. 2018;13(1):e0190205.

311. Yu Y, Li X, Blanchard J, Li Y, lqbal K, Liu F, et al. Insulin sensitizers improve learning and attenuate tau hyperphosphorylation and neuroinflammation in 3xTg-AD mice. J Neural Transm (Vienna). 2015;122(4):593-606.

312. Kang EB, Kwon IS, Koo JH, Kim EJ, Kim CH, Lee J, et al. Treadmill exercise represses neuronal cell death and inflammation during Abeta-induced ER stress by regulating unfolded protein response in aged presenilin 2 mutant mice. Apoptosis. 2013;18(11):1332-47.

313. MacPherson RE, Baumeister P, Peppler WT, Wright DC, Little JP. Reduced cortical BACE1 content with one bout of exercise is accompanied by declines in AMPK, Akt, and MAPK signaling in obese, glucose-intolerant mice. J Appl Physiol (1985). 2015;119(10):1097-104.

314. Lu Y, Dong Y, Tucker D, Wang R, Ahmed ME, Brann D, et al. Treadmill exercise exerts neuroprotection and regulates microglial polarization and oxidative stress in a Streptozotocin-induced rat model of sporadic Alzheimer's disease. J Alzheimers Dis. 2017;56(4):1469-84.

315. Belarbi K, Burnouf S, Fernandez-Gomez FJ, Laurent C, Lestavel S, Figeac M, et al. Beneficial effects of exercise in a transgenic mouse model of Alzheimer's disease-like tau pathology. Neurobiol Dis. 2011;43(2):486-94.

316. Elahi M, Motoi Y, Matsumoto SE, Hasan Z, Ishiguro K, Hattori N. Short-term treadmill exercise increased tau insolubility and neuroinflammation in tauopathy model mice. Neurosci Lett. 2016;610:207-12.

317. Lavagnino L, Arnone D, Cao B, Soares JC, Selvaraj S. Inhibitory control in obesity and binge eating disorder: a systematic review and meta-analysis of neurocognitive and neuroimaging studies. Neurosci Biobehav Rev. 2016;68: 714-26.

318. Chupel MU, Direito F, Furtado GE, Minuzzi LG, Pedrosa FM, Colado JC, et al. Strength training decreases inflammation and increases cognition and physical fitness in older women with cognitive impairment. Front Physiol. 2017:8:377.

319. Papenberg G, Ferencz B, Mangialasche F, Mecocci P, Cecchetti R, Kalpouzos $\mathrm{G}$, et al. Physical activity and inflammation: effects on gray-matter volume and cognitive decline in aging. Hum Brain Mapp. 2016;37(10):3462-73.

\section{Ready to submit your research? Choose BMC and benefit from:}

- fast, convenient online submission

- thorough peer review by experienced researchers in your field

- rapid publication on acceptance

- support for research data, including large and complex data types

- gold Open Access which fosters wider collaboration and increased citations

- maximum visibility for your research: over $100 \mathrm{M}$ website views per year

At BMC, research is always in progress.

Learn more biomedcentral.com/submissions 